\title{
Ra-dominance: A new dominance relationship for preference-based evolutionary multiobjective optimization
}

\author{
Juan Zou ${ }^{\mathrm{a}, \mathrm{b}}$, Qite Yang ${ }^{\mathrm{a}, *}$, Shengxiang Yang ${ }^{\mathrm{a}, \mathrm{c}}$, Jinhua Zheng, \\ ${ }^{a}$ Key Laboratory of Intelligent Computing and Information Processing (Ministry of \\ Education), Xiangtan University, Hunan, 411105, China \\ ${ }^{b}$ LED Lighting Research and Technology Center of Gui Zhou Tong Ren, Gui Zhou, 554300, \\ China \\ ${ }^{c}$ School of Computer Science and Informatics, De Montfort University, Leicester LE1 9BH, \\ $U . K$. \\ ${ }^{d}$ Hunan Provincial Key Laboratory of Intelligent Information Processing and Application, \\ Hengyang Normal University, Hengyang, 421002, China
}

\begin{abstract}
While traditional Pareto-based evolutionary multi-objective optimization (EMO) algorithms have shown an excellent balance between convergence and diversity on a wide range of practical problems with two or three objectives in real applications, the decision maker (DM) is interested in a unique set of solutions rather than the the whole population on Pareto optimal front (POF). In addition, Pareto-based EMO algorithms have some shortcomings in dealing with many-objective problems because of insuffcient selection pressure toward trade-off solutions. Due to the above, it is crucial to incorporate DM preference information into EMO and seek a representative subset of Pareto optimal solutions with an increase in the number of objectives. This paper proposes a new dominance relationship, called Ra-dominance, which can improve diversity among the Pareto-equivalent solutions increase the selection presure in evolutionary process. It has the ability to guide the population toward areas more responsive to the needs of the DM according to a reference point and prefer-
\end{abstract}

\footnotetext{
${ }^{\hbar}$ Fully documented templates are available in the elsarticle package on CTAN

* Corresponding author

Email addresses: zoujuan@xtu.edu.cn (Juan Zou), qiteyang@foxmail.com (Qite Yang), syang@dmu.ac.uk (Shengxiang Yang), jhzheng@xtu.edu.cn (Jinhua Zheng)
} 
ence angle. We use the new dominance relationship in the NSGA-II algorithm, and the efficacy and usefulness of the modified procedure are assessed through two- to ten-objective problems. Experimental results show that the algorithm applying this new dominance relationship is highly competitive when compared with four state-of-the-art preference-based EMO methods.

Keywords: evolutionary algorithm, reference point, decision maker, multiobjective optimization, dominance relationship

2018 MSC: 00-01, 99-00

\section{Introduction}

The research on evolutionary multiobjective optimization (EMO) has entered a flourishing period due to multiobjective evolutionary algorithms' (MOEAs) inherent competent characteristic when solving multiobjective optimization prob-

5 lems (MOPs) 1, 2, 3, 4. Specifically, MOEAs are able to find a solution set which converges to, and widely and evenly distributes on, the Pareto front (PF) of MOPs. In addition, MOEAs have been devised to solve the MOPs of various engineering problems such as power dispatch [5], hospital bed scheduling [6] and robot path planning [7]. Deb et al. 8 proposed an elitist non-dominated sorting genetic algorithm (NSGA-II) with a non-dominated sorting and crowding distance assignment mechanism to maintain diversity. Zitzler et al. 9] proposed an improved strength Pareto evolutionary algorithm (SPEA2), which uses a novel fitness assignment and an archive truncation technique. A multi-objective evolutionary algorithm based on decomposition (MOEA/D) was proposed by Zhang et al. [10, 11, which is the most typical decomposition-based MOEA. Many other efforts have been devoted to developing MOEAs in recent years, [12, 13, 14, 15, 16, 17.

However, a problem that almost all MOEAs face is that the proportion of non-dominated solutions becomes larger with an increase in the number of objectives. Having a greater proportion of non-dominated solutions leads to insufficient selection pressure, which means the algorithm cannot go forward to 
find optimal solutions. An effective way to solve this problem is to introduce the DM's preference information into the algorithm, so a new variant of ranking mechanism can increase selection pressure and guide the algorithm to search in a specific area.

As is widely recognized, DMs in real life are always interested in some specific subset of the obtained solutions. The purpose of EMO is to approximate the whole PF while the preference-based MOEAs aim to obtain a subregion of the $\mathrm{PF}$. This region of preferred optimal solutions close to or on the true PF is called the region of interest (ROI) [18. The solution in the ROI is more in line with the needs of DM, but it does not mean the non-dominant solution outside ROI is not the optimal solution of the problem. The preference information provided by the DM in the EMO could guide a more effective search. There are several models of preference information given by DMs in current researches. Depending on vary. The commonly used models include reference point, reference weights and preference angle, etc, while reference point is probably the most popular model in preference-based MOEAs. A reference point consists of $m$ continuous valued aspiration levels representing desirable objective values, which can be specified freely by the $\mathrm{DM}$ and can be either in feasible region or infeasible region as shown in Fig:1 Depending on when the DM provides his/her preference information in the optimization, multiobjective optimization methods can be classified into a priori, a posteriori and interactive methods [3, 19, 20, 21].

- a priori: The DM introduces the preference information before the search process and integrates the preference information into the EMO algorith$\mathrm{m}$ to guide the search process. A priori approaches have the advantage of helping the DM to completely objectively articulate the preference information in a precise and exact manner regarding the objectives to be optimised thereby simplifying the optimization process 22. However, this method still has drawback, that the preference information may be unknown, especially when the DM has little information about the MOP. 


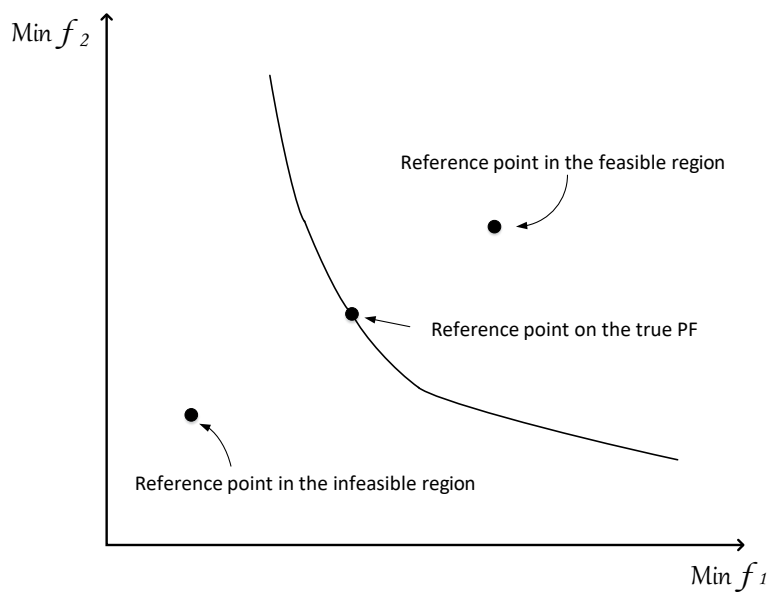

Figure 1: Illustration of the location of reference point

- a posteriori: According to the preference information, the DM selects the trade-off solutions from the whole approximate PF when the search process is completed. The advantage of this type of approach is that the DM does not need to offer his/her preference information before the computation 23. However, there is an obvious drawback that approximating the whole PF requires a large amount of computation.

- interactive: The preference information is injected during the search, so the DM can learn from the search and express his/her preferences interactively. The interactive approaches have become more widely used in preference-based MOEAs. However, the drawback of this approach is that the DM must be involved intensively during the whole search process 24].

Recently, much research has been conducted on preference-based MOEAs. Preference information of the DM was first introduced in EA by Fonseca et al. 65 25] 26]. Cvetkovic et al. 27] 28] used a fuzzy matrix to change the preference information into an objective weight and modified the Pareto relationship based on the weight. Molina et al. [29] proposed a modified dominance relationship called g-dominance by adding the location information of the reference point into the Pareto dominance. Said et al. [30] proposed a new order relationship called 
r-dominance, which can obtain good performance on many-objective problems when the reference point is in the infeasible region. Deb proposed a series of preference-based MOEAs, [31, 32, 33, 34, 35, which focus on finding a set of preferred solutions during the evolutionary process. In addition, Some value functions were proposed to guide the searching process towards the ROI by 75 Greco et al. [36. Another representative preference-based MOEA is WASFGA proposed by Ruiz et al. 37. Simultaneously, a new method for generating reference point from the expected level of the objective function was proposed in this paper. Yu et al. [38] decomposed the preference information into a number of scalar optimization problems based on MOEA/D. Hu et al.24 proposed a model that uses the preference selection radius and reference point to determine ROI.

In this paper, we propose a new dominance relationship called referencepoint-and-angle-based dominance (Ra-dominance). As a preference selection mechanism, this proposed new relationship plays an important role in creating a strict partial order between Pareto-equivalent solutions without modifying the main architecture of any specific MOEA. After integrating it into the NSGA-II algorithm and making contrast experiments with other state-of-the-art preference-based MOEAs, the Ra-dominance has shown the following abilities:

- Can assist the MOEA in obtaining different ranges of ROI in terms of the DM's preference information.

- Has good performance when the reference point is in different regions.

- Can easily control the range of obtained ROI.

- Has better and competitive results compared to other preference mechanisms on many-objective problems.

The remainder of this paper is organized as follows. In Section 2, we introduce related works on MOEAs, including some basic concepts and a brief description of the state-of-the-art preference-based MOEAs. Section 3 first illustrates the proposed Ra-dominance relationship, and then a Ra-dominance-based 
MOEA framework is introduced in detail. The parameters of Ra-dominance are analyzed in Section 3, and in Section 4, the experimental results are presented and discussed. Finally, conclusions are given in Section 5.

\section{Related Works}

\subsection{Basic concepts}

Without loss of generality, all the objectives in this paper are minimized, since maximization could be easily transformed to minimization. A multiobjective optimization problem can be defined as follows:

$$
\begin{aligned}
& \text { minimize }: F(\mathbf{x})=\left(f_{1}(\mathbf{x}), f_{2}(\mathbf{x}), \cdots, f_{m}(\mathbf{x})\right)^{T} \\
& \text { subject to }: \mathbf{x} \in \Omega
\end{aligned}
$$

such that

$$
\begin{array}{ll}
g_{i}(\mathbf{x}) \leq 0 & i=1, \cdots, P \\
h_{j}(\mathbf{x})=0 & j=1, \cdots, Q
\end{array}
$$

where $\Omega$ is the decision (variable) space, $\mathbf{x}=\left(x_{1}, \cdots, x_{n}\right)^{T} \in \Omega$ is a candidate solution; $F: \Omega \rightarrow R^{m}$ represents $m$ real-value objective functions; $R^{m}$ denotes the objective space, and $g_{i}(\mathbf{x})$ and $h_{j}(\mathbf{x})$ are the constraints of the problem.

Definition 1: (Pareto dominance relation): Given two individuals $\mathbf{x}$ and $\mathbf{y}, \mathbf{x}$ is said to Pareto dominate $\mathbf{y}$ if and only if:

$$
\begin{aligned}
& \forall i \in 1, \cdots, m, f_{i}(\mathbf{x}) \leq f_{i}(\mathbf{y}) \text { and } \\
& \exists j \in 1, \cdots, m, f_{i}(\mathbf{x})<f_{i}(\mathbf{y}) .
\end{aligned}
$$

Definition 2: (Pareto - optimal): $\mathbf{x}^{*} \in \Omega$ is said to be Pareto - optimal if there does not exit another $\mathbf{x} \in \Omega$ such that $\mathbf{x}$ dominating $\mathbf{x}^{*}$.

Definition 3: (Pareto optimal set): The Pareto optimal set PS is defined as:

$$
P S=\{\mathbf{x} \in \Omega \mid \mathbf{x} \text { is Pareto - optimal }\} .
$$

Definition 4: (Pareto front): The Pareto front $(P F)$ is defined as:

$$
P F=\left\{F(\mathbf{x}) \in R^{m} \mid \mathbf{x} \in P S\right\} .
$$




\subsection{The g-dominance}

110 g-dominance, which combines the reference point information with the traditional Pareto dominance relationship. The g-dominance definition can obtain a desired region via a MOEA without varying any parameters. The g-dominance relationship is defined as follows:

$$
\operatorname{Flag}_{g}(\mathbf{x})=\left\{\begin{array}{lll}
1 & \text { if } \quad g_{i} \leq f_{i}(\mathbf{x}), & \forall i=1,2, \cdots, m ; \\
1 & \text { if } \quad f_{i}(\mathbf{x}) \leq g_{i}, & \forall i=1,2, \cdots, m ; \\
0 & \text { otherwise }
\end{array}\right.
$$

$g$ is the reference point in objective sapce.

As shown in Fig,2, there are two camps of regions $($ Flag $=0$ and Flag $=1)$ divided by the dotted line in the objective space. The solutions in the regions with Flag $=0$ are g-dominated by the solutions in the regions with Flag $=1$ and the ROIs are marked with rough curves whether the reference point is in the feasible region or the infeasible region. However, the g-NSGA-II does not have good performance while the reference point is on or close to the true PF 30$]$.

\subsection{The r-dominance}

The r-dominance relationship was proposed by Said et al. [30. This dominance relationship prefers solutions that are closer to the reference point based on a weighted Euclidean distance employed by Deb [31. This new relationship markedly increases the selection pressure and helps the r-dominance-based algorithm to search for preferred solutions. The r-dominance relationship is defined as follows:

Given two solutions $\mathbf{x}$ and $\mathbf{y}, \mathbf{x}$ r-dominates $\mathbf{y}$ if: 


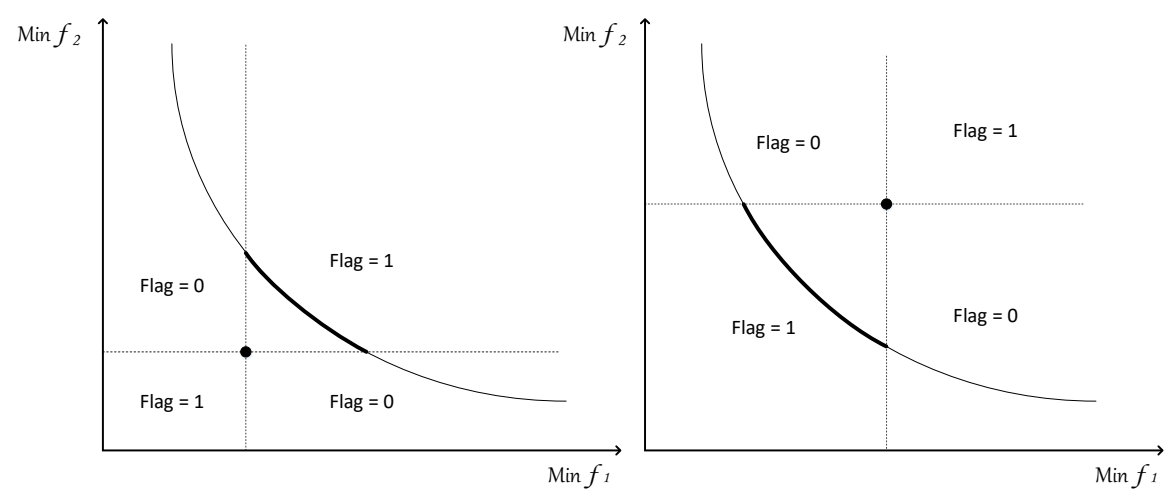

Figure 2: Illustration of $g$-dominance in 2-objective space

1. $\mathbf{x}$ dominates $\mathbf{y}$ in the Pareto sense, or

2. $\mathbf{x}$ and $\mathbf{y}$ are Pareto-equivalent and $D(\mathbf{x}, \mathbf{y}, g)<-\delta$, where $\delta \in[0,1]$ is termed the non-r-dominance threshold; $g$ is the reference point and

$$
\begin{gathered}
D(\mathbf{x}, \mathbf{y}, g)=\frac{\operatorname{Dist}(\mathbf{x}, g)-\operatorname{Dist}(\mathbf{y}, g)}{\text { Dist }_{\text {max }}-\operatorname{Dist}_{\text {min }}} \\
\operatorname{Dist}_{\text {max }}=\operatorname{Max}_{\mathbf{z} \in P} \operatorname{Dist}(\mathbf{z}, g), \\
\operatorname{Dist}_{\text {min }}=\operatorname{Min}_{\mathbf{z} \in P} \operatorname{Dist}(\mathbf{z}, g) .
\end{gathered}
$$

The weighted Euclidean distance is defined as:

$$
\operatorname{Dist}(\mathbf{z}, g)=\sqrt{\sum_{i=1}^{m} \omega_{i}\left(\frac{f_{i}(\mathbf{z})-g_{i}}{f_{i}^{\text {max }}-f_{i}^{\text {min }}}\right)^{2}}
$$

where $\omega_{i} \in[0,1], \sum_{i=1}^{m} \omega_{i}=1 ; f_{i}^{\max }$ and $f_{i}^{\text {min }}$ are the upper and lower bound of the $i$ th objective value, and $\omega_{i}$ is the weight associated with $i$ th objective.

However, when the reference point is in the feasible region, the ROI obtained by r-NSGA-II has poor convergence. Equation 1 and Equation 3 show that the desired region obtained by r-NSGA-II depends on the location of the reference 
point. The solutions guided by the reference point may approximate the region away from the true POF when the reference point is in the feasible region.

Hu et al. 24 proposed a preference-based MOEA using a preference selection radius called p-NSGA-II. In this approach, the DM needs to provide a radius of the ROI and a reference point, which is used for confirming the reference direction. After that, a new selection mechanism in the approach constructs a preference radius $d_{p}$ to divide the whole population into two distinct parts (preferenced part and non-preferenced part) and selects the optimal solutions in the preferenced part. The preference radius is defined as:

$$
d_{p}=\sum_{i}^{N} d_{p_{i}} / N
$$

where $d_{p_{i}}$ is the distance from solution $i$ to the reference direction.

Algorithm 1 presents the proposed selection mechanism. This selection mechanism can enhance convergence and can be applied to deal with some many-objective problems.

\subsection{WASF-GA}

The weighting achievement scalarizing function genetic algorithm (WASFGA) was proposed by Ruiz et al. [37, that uses a sample of weight vector $\mathbf{w}$ in $(0,1)^{m}$ and a reference point $g$ to execute achievement scalarizing function (ASF). And based on the value of each solution obtained by ASF, the population can be classified into several fronts. The ASF function is shown as follows:

$$
s(g, f(\mathbf{x}), \mathbf{w})=\max _{i=1, \cdots, m}\left\{w_{i}\left(f_{i}(\mathbf{x})-g_{i}\right)\right\}+\rho \sum_{i=1}^{k} w_{i}\left(f_{i}(\mathbf{x})-g_{i}\right),
$$

which must be minimized over $\Omega$ :

$$
\text { minimize } s(g, f(\mathbf{x}), \mathbf{w}) \text {, subject to } \mathbf{x} \in \Omega \text {, }
$$

where $\rho$ is a parameter which must be a small positive value. 


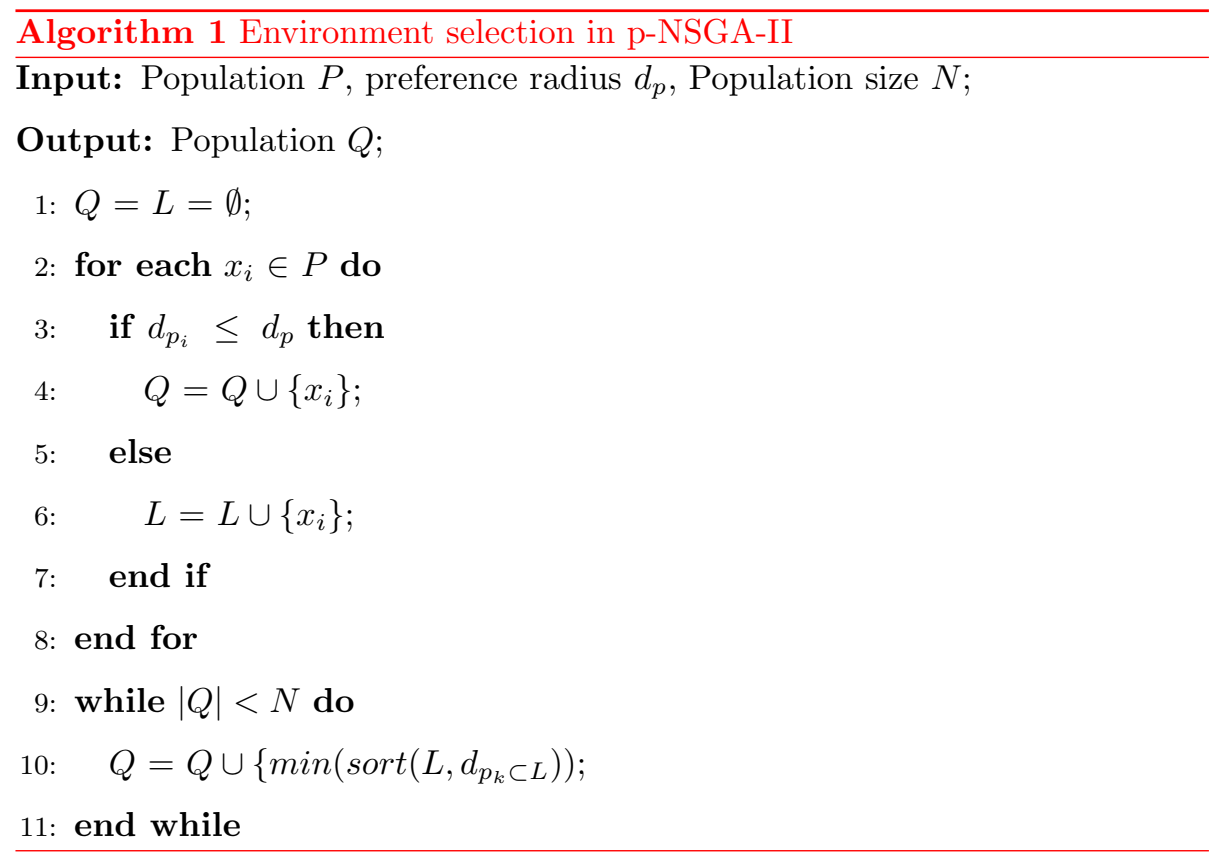

Like g-NSGA-II, WASF-GA is designed to approximate a very particular ROI that contains solutions dominated by the reference point (when it is infeasible) or solutions which dominate the reference point ( when it is feasible). WASF-GA is an representational preference-based MOEA using the reference points and ASF function. And another feature is that the DM does not need to set any extra parameter. Overall, WASF-GA is an efficient approach.

\section{The proposed approach}

In this section, we detail the proposed approach. Firstly, a new dominance relationship, called Ra-dominance, which takes its origin from Pareto dominance, is proposed. Then we modify NSGA-II by the Ra-dominace, thereby creating the Ra-NSGA-II algorithm. Finally, the effect of the reference point location and preference angle on the new dominance relationship is illustrated. 


\subsection{Definition of Ra-dominance}

MOEA is one of the most popular ways to deal with a wide range of MOPs even though it still has some problems to overcome. The number of nondominated solutions significantly increases once the number of objectives increases, and the traditional Pareto dominance relationship does not induce sufficient selection pressure toward a set of trade-off solutions. The Ra-dominance relationship blends in preference information, which can alleviate the loss of selection pressure and help the population to converge close to the reference point and reference direction as much as possible.

The process of our approach to determine the ROI is simple and convenient. Usually, the DM prefers solutions that are closer to the DM's preferences (reference point or reference direction). For the sake of this goal, reference direction must be confirmed first. Reference direction $v$ is defined as the vector from reference point $g$ to solution $x_{\text {near }}$, which is the nearest (weighted distance) solution to $g$ in the population. For a solution $\mathbf{x}$, its weighted distance is defined as:

$$
d i s_{x}=\sqrt{\sum_{i=1}^{m} \omega_{i}\left(g_{i}-f(\mathbf{x})_{i}\right)^{2}}
$$

where $\omega_{i} \in[0,1], \sum_{i=1}^{m} \omega_{i}=1 ; \omega_{i}$ is the weight associated with $i$ th objective given by the DM.

After determining the reference direction, an adjustable preference radius in accordance with the preference angle and the distance from $g$ to $x_{n e a r}$ can be confirmed, which can control the preference range by the DM. Preference radius $r$ is defined as:

$$
r=\operatorname{dist}\left(g, x_{n e a r}\right) \cdot \tan \alpha
$$

where $\operatorname{dist}\left(g, x_{\text {near }}\right)$ is the Euclidean distance between $g$ and $x_{n e a r}, \alpha \in\left(0,90^{\circ}\right)$ is the preference angle.

However, the DM may need a intuitive parameter to define the range of ROI. SO we introduce an intuitive and understandable way to control the range of ROI. Here, we use a threshold $\delta(0<\delta \leq 1)$ as the ratio of the ROI to 


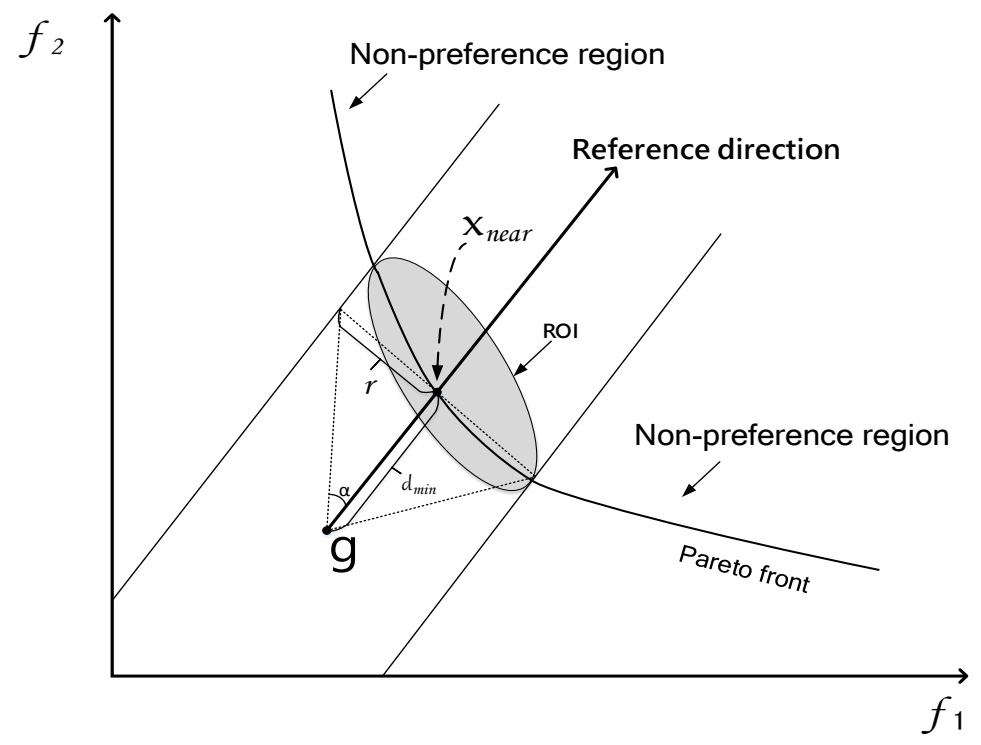

Figure 3: An example of ROI in two-objective space

the whole PF. Given $\delta$, collected as additional preference information elicited by the DM, Equation 7 is given for setting the corresponding $\alpha$ value.

$$
\alpha= \begin{cases}\delta \cdot \frac{\pi}{2} & \text { if } 0<\delta<1 \\ \left(1-10^{-4}\right) \cdot \frac{\pi}{2} & \text { if } \delta=1 .\end{cases}
$$

In Section 3.3 to 3.5, we explain the effect of weight, reference point and threshold on the ROI in detail. Fig 3 shows an example in two-objective space with $\omega=(0.5,0.5)$, where the gray area represents the ROI. Algorithm 2 presents the preferences' processing in detail.

The Ra-dominance relationship: Assuming a population of $P$, a reference direction vector $v$ and a reference radius $r$, a solution $\mathbf{x}$ is said to Ra190 dominate a solution $\mathbf{y}$ if :

1) $\mathbf{x}$ dominates $\mathbf{y}$ in the Pareto sense, or

2) $\mathbf{x}$ and $\mathbf{y}$ are Pareto-equivalent and

$$
d(\mathbf{y}, v)-d(\mathbf{x}, v)>r
$$




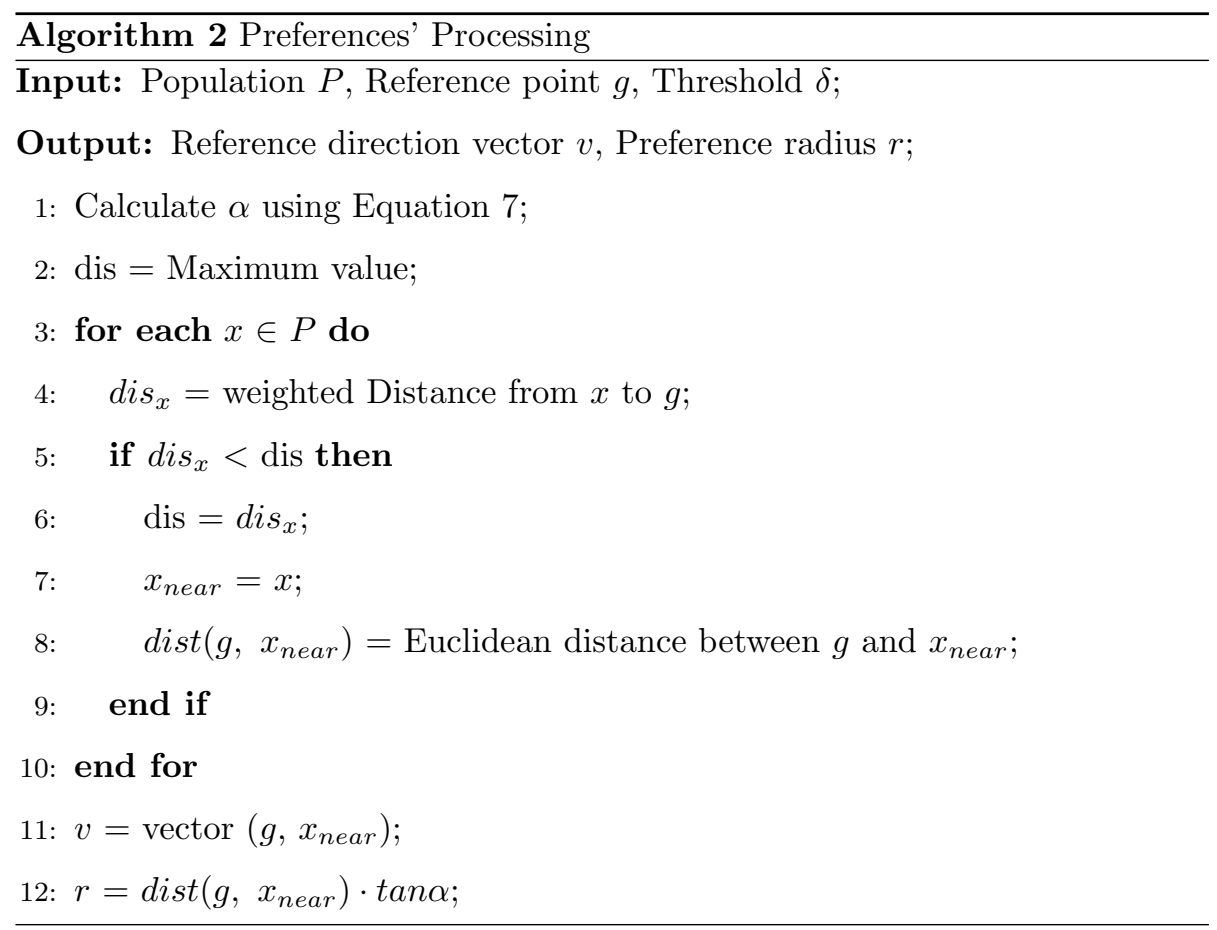

where $d(\mathbf{x}, v)$ represents the perpendicular distance from solution $\mathbf{x}$ to vector $v$, and $r$ is the preference radius. Algorithm 3 introduces how to decide the Ra-dominance relationship between two solutions.

The definition of Ra-dominance shows that this new dominance relationship not only has the ability to guide the entire population to approximate the true PF with Pareto dominance but also can make sure a strict partial order between Pareto-equivalent solutions by Equation 8, which makes solutions closer to the reference direction vector have more selected opportunity to be retained. Furthermore, Ra-dominance is capable of expanding the diversity among the population and increasing the likelihood of solutions being selected within the ROI. In addition, the preference radius $r$ is a controller regulating the range of the ROI. Fig 4 gives an example of the classification of a population of 18 solutions using the Ra-dominance principle and the Pareto-dominance principle, in which the reference point is shown with a filled black pentagram. The non-Pareto dominance rank is marked on the lower left of the solution and 


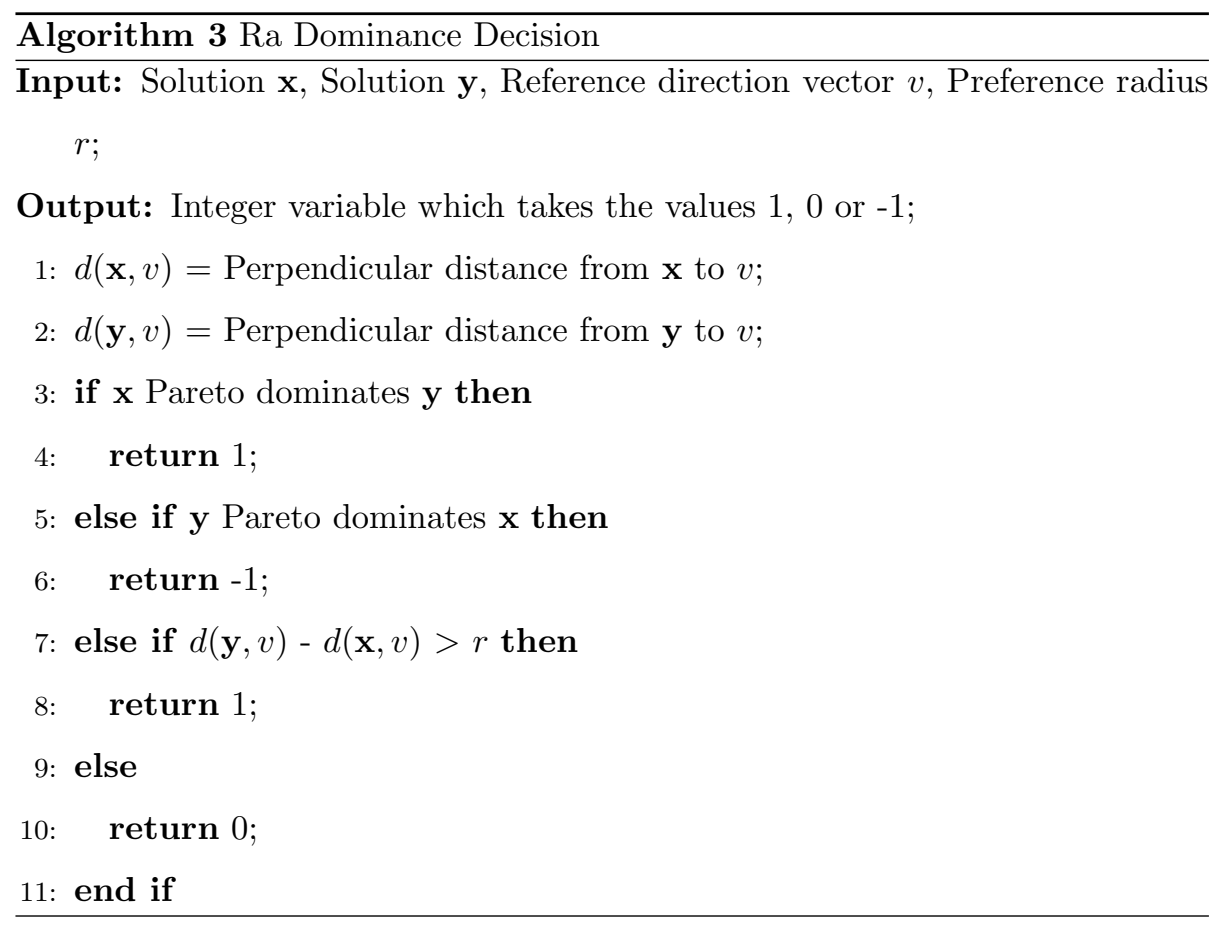

the non-Ra dominance rank is marked on the lower right of the solution. It is clear from Fig 4 that the solutions in the ROI have the same rank in both circumstances. However, the solutions which locate $n$ level on the non-Pareto dominance rank but outside of ROI have $n+1$ level on the non-Ra dominance rank. For example, if three solutions need to be chosen for the next evolution, solutions $\mathrm{a}, \mathrm{d}$, and $\mathrm{f}$ in the first non-Pareto-dominated front would be saved for the sake of the distribution of the population, while solutions b, c, and d in the first non-Ra dominance front would be chosen because of the preference information of the DM.

\subsection{Ra-dominance-based MOEA}

In this subsection, we propose Ra-NSGA-II which integrates the Ra-dominance relationship into NSGA-II. The algorithm starts with an initial parent population $P$. Secondly, a reference point $g$ and a threshold $\delta$ are given by the DM. Based on these two parameters, the preference range could be determined in 




Figure 4: Non-dominated sorting

the next progress. In the evolution process, an offspring population $Q$ is generated by performing any crossover operator and mutation operator on $P$. Then, the offspring population and the parent population are mixed to form a mixed population and preferences are processed further. After that, a new generation $P$ is picked from the mixed population $R$ by Environment Selection, which is presented in Algorithm 4 in detail. This process is repeated when the stopping criterion (for example, a maximum evolutionary generation predefined by the DM) are not met. While the search process is done, the final archive population $P$ is reported to the DM. In addition, this algorithm can be used interactively by asking the DM to provide a new reference point and threshold, and repeat it if the solutions do not meet the demand of the DM. The main step of Ra-NSGA-II is shown in Algorithm 5 .

\subsection{The Effect of Weight}

235

In this subsection, we investigate the effect of changing the weight vector of the weighted distance on the distribution of the obtained preferred solution- 


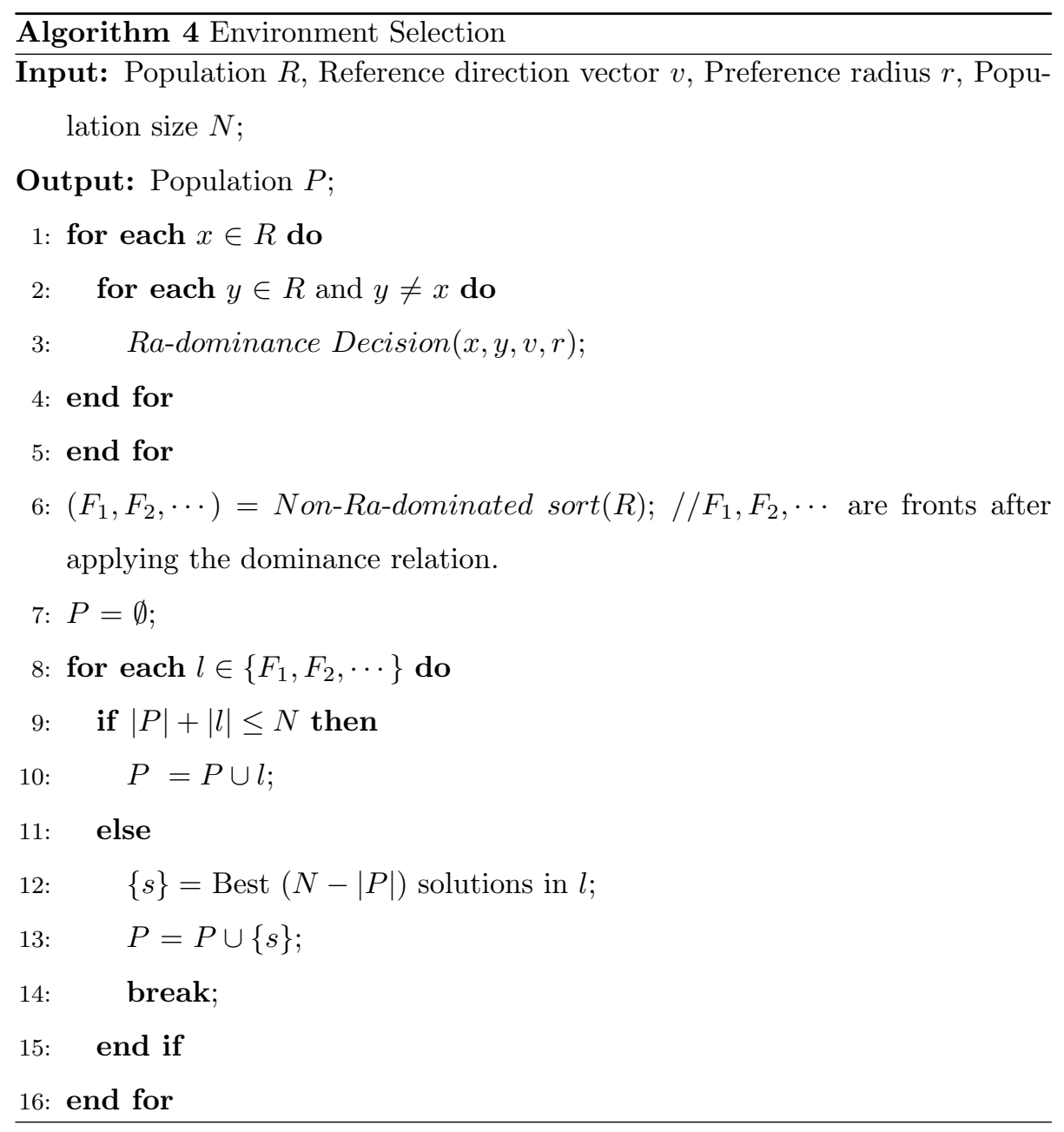

s. In this experiment, we use NSGA-II with Ra-dominance (Ra-NSGA-II) on ZDT2. The reference point is $(0.2,0.2), \delta=0.3$ and generation $=300$. Three independent experiment results with three different weight $((0.1,0.9),(0.5,0.5)$ and $(0.9,0.1))$ are given in Fig 5 . It is obvious that a bias on the distribution of the ROI solutions can be obtained by modifying the weight vector. For weight vector $(0.5,0.5)$, there is no bias among the obtained solutions. As for weight vector $(0.9,0.1)$, there is more emphasis on $f_{1}$, so obtaining solutions that optimize $f_{1}$ more than $f_{2}$. On the contrast, the opposite phenomenon can been seen for weight vector $(0.1,0.9)$. Once the DM wants to get better values for 


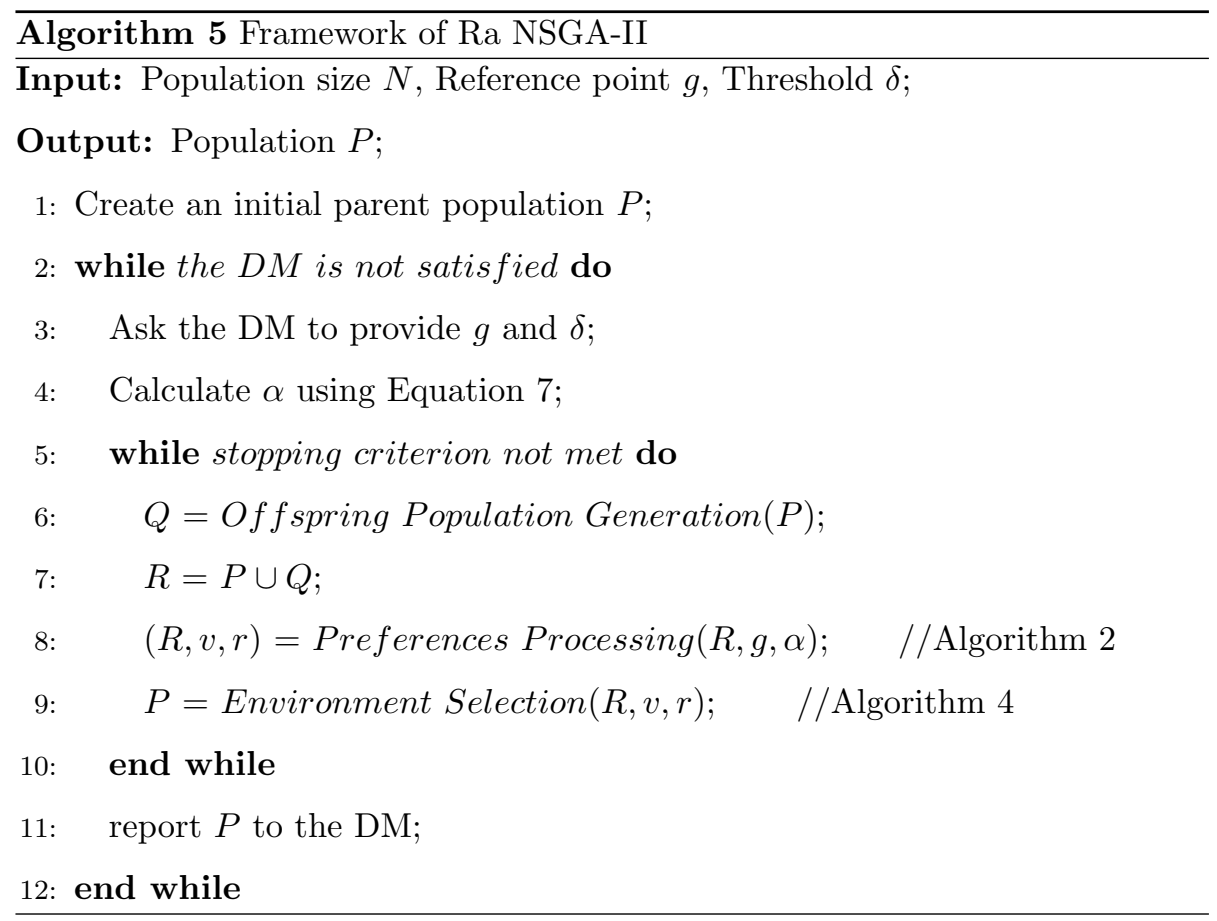

one objective function over the others, then he/she can just modify the weight vector. In the next series of experiments mentioned in this paper, if there is no specific explanation, then the weight vector is set as $\left(\frac{1}{m}, \frac{1}{m}, \cdots\right)(m$ is the number of objectives).

In this subsection, we study the effect of reference point position on the range of the ROI. In this experiment, we use Ra-NSGA-II and operate three different reference points, $g=(0.2,0.2), g=(0.5,0.5)$ and $g=(0.7,0.7)$, on the bi-objective DTLZ2 problem. The threshold $\delta$ is set as $\frac{1}{3}\left(\alpha=30^{\circ}\right)$. Fig 6 shows the effect of varying lengths of the radius of the ROI with three different reference points. It is clear that the range of the ROI increases with the increase of the distance from the reference point to the PF. When the reference point is far enough from the PF, it loses its valid information for solving the problem and the range of the obtained ROI covers the whole true PF. On the contrary, 


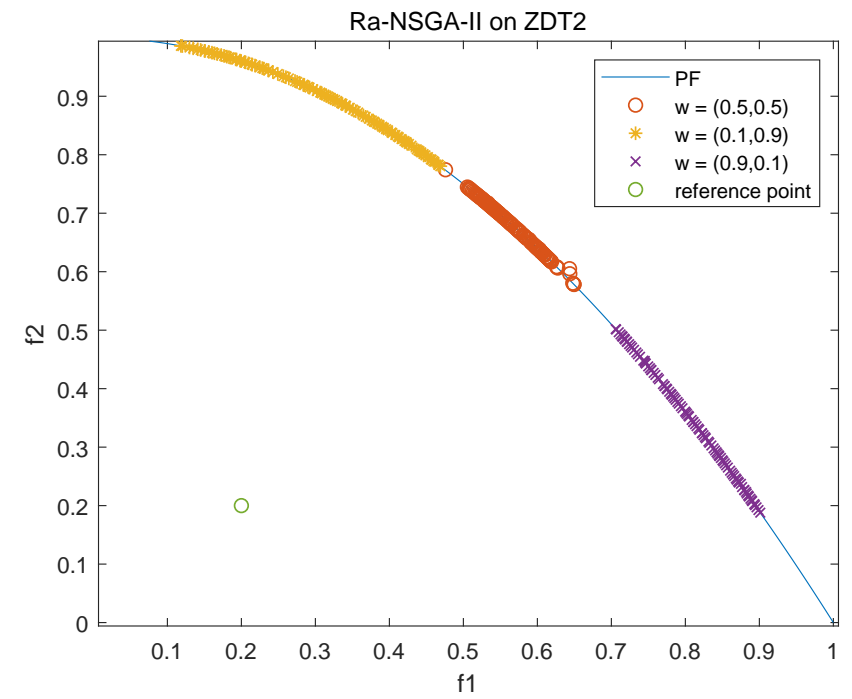

Figure 5: Three independent Ra-NSGA-II on ZDT2 $(\delta=0.3)$

obtained solution set would shrink very small and close to the reference point if the reference point on the true PF. In this situation, the threshold will lose its dominance over the range of ROI control. This characteristic well reflects the influence of the accuracy of preference information given by the DM on the final solution set, which indicates that the DM's ROI needs to be more precise when the reference point is closer to the PF.
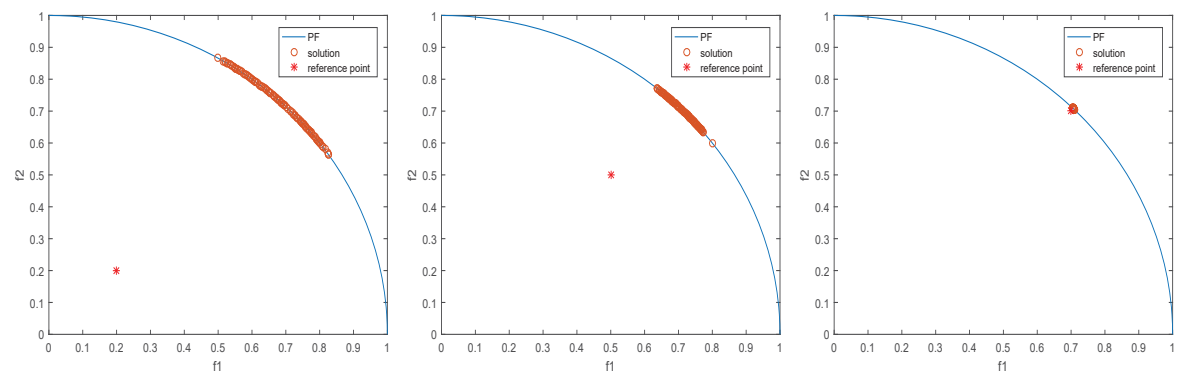
(a) $g=(0.2,0.2)$
(b) $g=(0.5,0.5)$
(c) $g=(0.7,0.7)$ 


\subsection{The Effect of Threshold}

Based on the above content, we utilize Ra-NSGA-II to study the effect of threshold on the range of the ROI. In order to determine the effect, we first need to identify a reference point that will not change. Fig 7 and Fig 8 show the preference range with three different preference threshold $(\delta=0.2,0.5$ and 1) on ZDT3 and 2-objective DTLZ2 problem, in which the reference points were $(0.1,-0.4)$ in ZDT3 and $(0.4,0.4)$ in 2-objective DTLZ2. From Fig, 7 and Fig 8 , we notice that the range of obtained ROI is positively related to the size of the preference angle and could cover or approximate the whole PF when the $\delta$ is equal to 1 . The introduction of the threshold $\delta$ enables the DM to adjust the preference range according to the characteristics of the problem, which is very important in practical problems. Because of the effect of reference point position, as we illustrated in Subsection 3.4 the ROI will shrink to a minimal extent when the reference point is very close to or on the PF. So in this time, the threshold is no longer dominant in determining the range of ROI. If the DM still want a larger ROI, then what he/she needs to do is adjusting the position of reference point interactively.

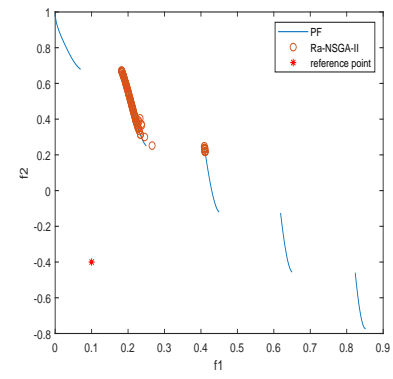

(a) $\delta=0.2\left(\alpha=18^{\circ}\right)$

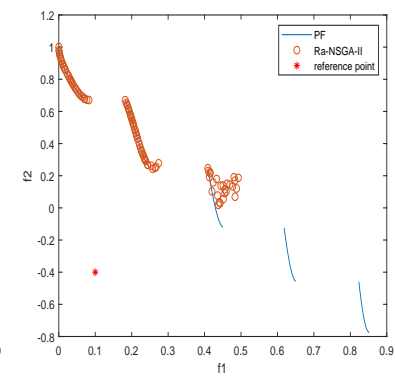

(b) $\delta=0.5\left(\alpha=45^{\circ}\right)$

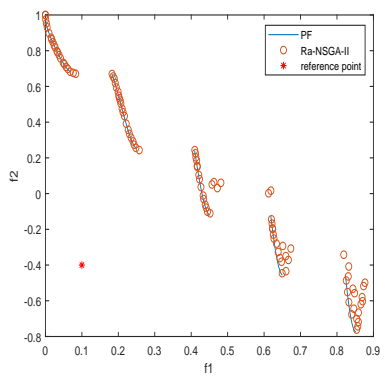

(c) $\delta=1\left(\alpha=89.991^{\circ}\right)$

Figure 7: Ra-NSGA-II with three different preference angles on the ZDT3

\subsection{Comparison Between Ra-dominance and r-dominance}

As another reference-point-based dominance relationship for decision mak- 


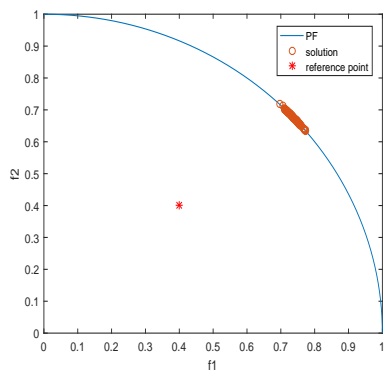

(a) $\delta=0.2$

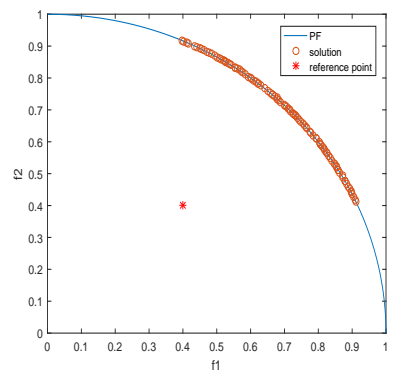

(b) $\delta=0.5$

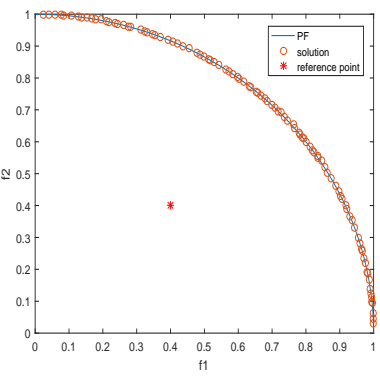

(c) $\delta=1$

Figure 8: Ra-NSGA-II with three different preference angles on the 2-objective DTLZ2

relationship in building new non-dominated sorting. First of all, both use the reference point as additional information in the objective space to redefine new dominance relationships, which could substitute for the traditional selection process. Secondly, They both require the reference point and a parameter controlling the range of the obtained ROI. In addition, the key feature of these two dominance relationships is that they prefer solutions that are closer to the reference point while preserving the order induced by Pareto dominance.

However, there are two differences between Ra-dominance and r-dominance. One is that only the distances from the reference point to individuals are considered in the r-dominance relationship to modify the non-dominated sorting, which means r-dominance will blindly guide the population to approach to a region close to the reference point. When the reference point is within the feasible domain, the reference point guides the population away from the PF, which prohibits the population from converging to the true PF. However, in the Ra-dominance relationship, the individual closest to the reference point is considered as the center of preference and a reference direction is introduced. Meanwhile, the distance from individual to reference point is replaced by the distance from individual to reference direction. This strategy could correctly guide the search direction of the algorithm even when the reference point is within the feasible domain. A comparison experiment of Ra-NSGA-II and r-NSGA-II on 


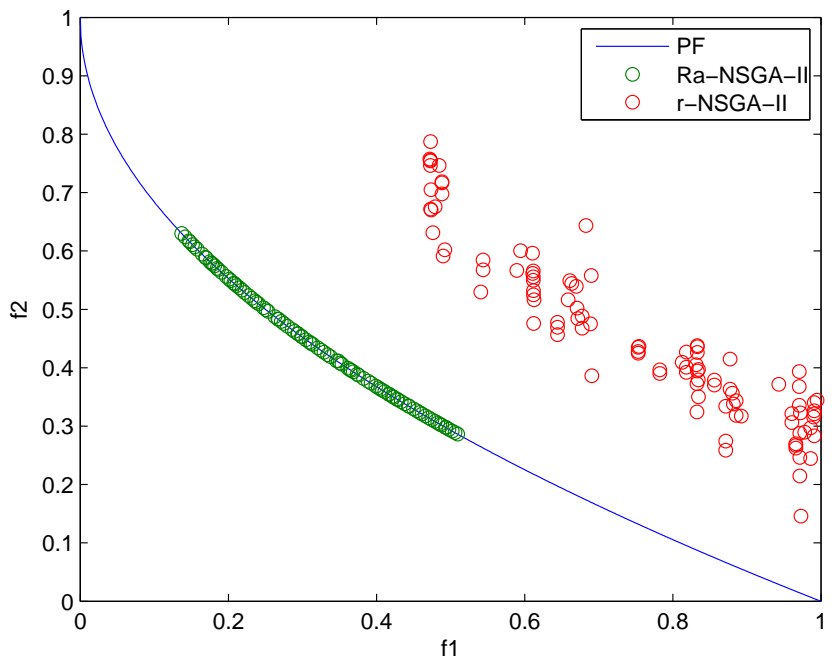

Figure 9: Two preference-based NSGA-II on ZDT1, $g=(2.5,2.5)$

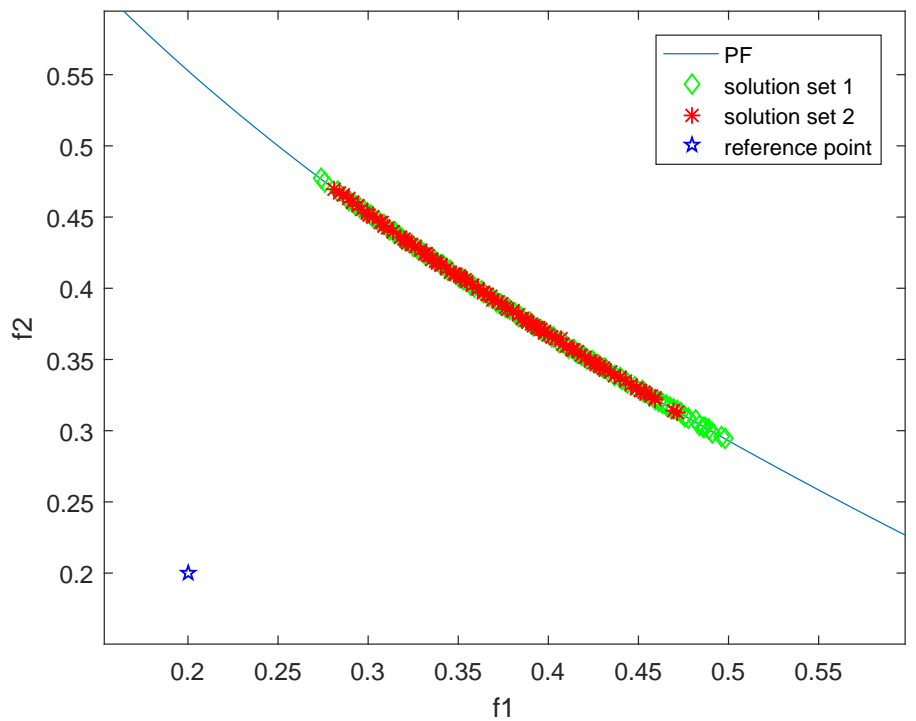

Figure 10: Two independent r-NSGA-II on ZDT1 $(\delta=0.7, \omega=(0.5,0.5))$ 
ZDT1 is given in Fig.9. In this comparison experiment, both algorithms used the same number of evaluations and operators, which were the same as used in Section 4. The reference point was $(2.5,2.5)$, and the threshold $\delta$ was 0.3 . It is clearly that when reference point in the feasible region and far away from the PF, the r-NSGA-II loses the ability to guide search while the Ra-NSGA-II can guide the solutions converge to the true PF.

Another drawback of r-dominance is that the scope of its obtained ROI is varied when repeatedly performing independent experiments with the same parameters, although a threshold $\delta$ is used to limit a blur range of the ROI. Fig 10 shows an example of two independent r-NSGA-II on bi-objective ZDT1, where the green diamond and red rectangle respectively represent the solution set obtained by the two experiments. The preference angle in Ra-dominance could help to control a precise preference range and make the DM satisfied with enlarging or reducing the range during evolution.

However, our method is a little similar to p-NSGA-II, which also uses a radius to determine the range of ROI. The difference is that the range of ROI in Ra-dominance is determined not only a preference angle but also the position of reference point. This means the radius in Ra-dominance is affected by the reference point, preference angle and the shape of true PF. Moreover, the framework 325 of p-NSGA-II is very complicated since its main operation is in the environment selection, so that the computational complexity grows sharply with an increase in the number of generations. However, Ra-dominace just modifies the Pareto dominance relationship and can be used in any Pareto-based framework, as a same advantage as r-dominace. Overall, Ra-dominance has the advantages of both r-dominance and p-NSGA-II, and avoids their disadvantages.

\section{Experimental Study}

To investigate the performance of the Ra-NSGA-II, contrast experiments with four state-of-the-art perference-based MOEAs: g-NSGA-II, r-NSGA-II, pNSGA-II and WASF-GA are designed. First of all, we describe the performance 
The GD value is defined as:

$$
G D=\frac{\sqrt{\sum_{x \in P} d_{\min }^{2}(x, P F)}}{|P|},
$$

where $|P|$ is the number of solutions in the obtained solution set $P$, and $d_{\min }(x, P F)$ is the distance between solution $x$ in $P$ and the nearest member in the true PF. The smaller the GD value, the better the convergence of the algorithm.

The SP value is defined as:

$$
S P=\sqrt{\frac{1}{|P|-1} \sum_{i=1}^{|P|}\left(\bar{d}-d_{i}\right)^{2}},
$$

where

$$
d_{i}=\min _{j \in 1,2, \cdots,|P|}\left\{\sum_{m=1}^{k}\left|f_{m}\left(x_{i}\right)-f_{m}\left(x_{j}\right)\right|\right\},
$$

where $x_{i}, x_{j} \in P(i=1,2, \cdots,|P|)$ and $x_{i} \neq x_{j} ; \bar{d}$ is the average value of all the $d_{i}$, and $k$ is the number of objectives. The smaller the SP value, the more uniform the distribution. 
Table 1: Reference point and parameters setting in different algorithms and instances

\begin{tabular}{|c|c|c|c|c|c|c|}
\hline Instance & Generation & & $g$ & $\delta$ in r-NSGA-II & $d_{p}$ in p-NSGA-II & $\delta$ in Ra-NSGA-II \\
\hline \multirow{3}{*}{ ZDT1 } & \multirow{3}{*}{300} & infeasible region & $(0.1,0.2)$ & 0.7 & 0.4 & 0.65 \\
\hline & & close to PF & $(0.5,0.3)$ & 0.05 & 0.02 & 0.04 \\
\hline & & feasible region & $(0.5,0.6)$ & 0.4 & 0.3 & 0.5 \\
\hline \multirow{3}{*}{ ZDT2 } & \multirow{3}{*}{300} & infeasible region & $(0.1,0.2)$ & 0.8 & 0.45 & 0.7 \\
\hline & & close to PF & $(0.6,0.64)$ & 0.05 & 0.02 & 0.05 \\
\hline & & feasible region & $(0.7,0.6)$ & 0.15 & 0.1 & 0.2 \\
\hline \multirow{3}{*}{ ZDT3 } & \multirow{3}{*}{300} & infeasible region & $(0.1,0.2)$ & 0.4 & 0.2 & 0.25 \\
\hline & & close to PF & $(0.24,0.28)$ & 0.05 & 0.02 & 0.05 \\
\hline & & feasible region & $(0.4,0.6)$ & 0.3 & 0.15 & 0.3 \\
\hline \multirow{3}{*}{ ZDT4 } & \multirow{3}{*}{600} & infeasible region & $(0.1,0.2)$ & 0.7 & 0.4 & 0.65 \\
\hline & & close to PF & $(0.5,0.3)$ & 0.05 & 0.02 & 0.04 \\
\hline & & feasible region & $(0.5,0.6)$ & 0.4 & 0.3 & 0.5 \\
\hline \multirow{3}{*}{ DTLZ1 } & \multirow{3}{*}{1000} & infeasible region & $(0.1,0.2,0.1)$ & 0.4 & 0.1 & 0.35 \\
\hline & & on $\mathrm{PF}$ & $(0.1,0.2,0.2)$ & 0.05 & 0.02 & 0.05 \\
\hline & & feasible region & $(0.3,0.4,0.5)$ & 0.7 & 0.2 & 0.65 \\
\hline \multirow{3}{*}{ DTLZ2 } & \multirow{3}{*}{300} & infeasible region & $(0.1,0.2,0.1)$ & 0.85 & 0.45 & 0.8 \\
\hline & & close to PF & $(0.4,0.8,0.45)$ & 0.05 & 0.02 & 0.05 \\
\hline & & feasible region & $(0.7,0.8,0.9)$ & 0.5 & 0.3 & 0.5 \\
\hline \multirow{3}{*}{ DTLZ3 } & \multirow{3}{*}{1000} & infeasible region & $(0.1,0.2,0.1)$ & 0.85 & 0.45 & 0.8 \\
\hline & & close to PF & $(0.4,0.8,0.45)$ & 0.05 & 0.02 & 0.05 \\
\hline & & feasible region & $(0.7,0.8,0.9)$ & 0.5 & 0.3 & 0.5 \\
\hline \multirow{3}{*}{ DTLZ4 } & \multirow{3}{*}{300} & infeasible region & $(0.1,0.2,0.1)$ & 0.85 & 0.45 & 0.8 \\
\hline & & close to PF & $(0.4,0.8,0.45)$ & 0.05 & 0.02 & 0.05 \\
\hline & & feasible region & $(0.7,0.8,0.9)$ & 0.5 & 0.3 & 0.5 \\
\hline \multirow{3}{*}{ DTLZ5 } & \multirow{3}{*}{300} & infeasible region & $(0.1,0.2,0.1)$ & 0.7 & 0.45 & 0.8 \\
\hline & & close to PF & $(0.3,0.3,0.9)$ & 0.05 & 0.02 & 0.05 \\
\hline & & feasible region & $(0.7,0.7,0.9)$ & 0.6 & 0.3 & 0.7 \\
\hline \multirow{3}{*}{ DTLZ6 } & \multirow{3}{*}{1000} & infeasible region & $(0.1,0.2,0.1)$ & 0.7 & 0.45 & 0.8 \\
\hline & & close to PF & $(0.3,0.3,0.9)$ & 0.05 & 0.02 & 0.05 \\
\hline & & feasible region & $(0.7,0.7,0.9)$ & 0.6 & 0.3 & 0.7 \\
\hline
\end{tabular}

\subsection{Parameter Setting}

In our experiments, we used the simulated binary crossover operator with a distribution index of 20 and polynomial mutation with a distribution of 20 . The crossover probability and mutation probability were respectively set as $P_{c}$ $=0.99$ and $P_{m}=0.08$. The size of the population was 100. As for r-NSGA-II, the weight vector $w$ was set as $\left(\frac{1}{m}, \frac{1}{m}, \cdots\right)$. The generation of weight vectors used in WASF-GA is same as used in MOEA/D. The implementation is made in Matlab, and the results below were achieved using MATLAB 2018a on an identical-computer with Intel(R) Core(TM) i5-3230M $2.60 \mathrm{GHz}$ and $4 \mathrm{~GB}$ of RAM. All algorithms were independently run 30 times.

\subsection{Experiment on two- and three-objective problems}

To inspect the effect of the reference points on the algorithms in different regions, we considerd three situations of the location of the reference points. In 
Table 2: Mean and standard deviation GD values on ZDT and 3-objective DTLZ

\begin{tabular}{|c|c|c|c|c|c|c|}
\hline Instances & $g$ & g-NSGA-II & r-NSGA-II & p-NSGA-II & WASF-GA & Ra-NSGA-II \\
\hline \multirow{3}{*}{ ZDT1 } & infeasible region & $8.01 \mathrm{E}-04(8.16 \mathrm{E}-04)+$ & $1.58 \mathrm{E}-04(4.66 \mathrm{E}-05)=$ & $4.82 \mathrm{E}-04(9.01 \mathrm{E}-05)+$ & $5.31 \mathrm{E}-04(1.19 \mathrm{E}-04)+$ & $3.61 \mathrm{E}-05(3.30 \mathrm{E}-05)$ \\
\hline & close to/on PF & $7.53 \mathrm{E}-05(4.05 \mathrm{E}-05)+$ & $4.76 \mathrm{E}-05(3.31 \mathrm{E}-05)=$ & $9.72 \mathrm{E}-05(1.75 \mathrm{E}-05)=$ & $5.05 \mathrm{E}-05(8.15 \mathrm{E}-06)+$ & $8.32 \mathrm{E}-06(3.51 \mathrm{E}-06)$ \\
\hline & feasible region & $2.63 \mathrm{E}-04(6.33 \mathrm{E}-05)+$ & $4.73 \mathrm{E}-04(3.22 \mathrm{E}-04)+$ & $3.15 \mathrm{E}-04(6.25 \mathrm{E}-05)+$ & $3.78 \mathrm{E}-04(9.17 \mathrm{E}-05)+$ & $8.23 \mathrm{E}-05(1.59 \mathrm{E}-05)$ \\
\hline \multirow{3}{*}{ ZDT2 } & infeasible region & $7.88 \mathrm{E}-04(3.02 \mathrm{E}-04)=$ & $3.80 \mathrm{E}-04(6.96 \mathrm{E}-05)=$ & $3.56 \mathrm{E}-04(7.85 \mathrm{E}-05)=$ & $7.97 \mathrm{E}-04(1.20 \mathrm{E}-04)=$ & $3.05 \mathrm{E}-04(9.39 \mathrm{E}-05)$ \\
\hline & close to/on PF & $3.01 \mathrm{E}-03(1.19 \mathrm{E}-02)+$ & $3.99 \mathrm{E}-04(1.30 \mathrm{E}-05)=$ & $1.10 \mathrm{E}-04(3.03 \mathrm{E}-05)=$ & $5.72 \mathrm{E}-05(8.14 \mathrm{E}-06)=$ & 7.93E-05(4.71E-05) \\
\hline & feasible region & $1.43 \mathrm{E}-04(2.70 \mathrm{E}-05)=$ & $1.77 \mathrm{E}-04(3.10 \mathrm{E}-04)=$ & $1.12 \mathrm{E}-04(2.40 \mathrm{E}-05)=$ & $1.88 \mathrm{E}-04(9.48 \mathrm{E}-05)=$ & $7.48 \mathrm{E}-05(2.33 \mathrm{E}-05)$ \\
\hline \multirow{3}{*}{ ZDT3 } & infeasible region & $1.05 \mathrm{E}-03(1.41 \mathrm{E}-03)+$ & $7.42 \mathrm{E}-04(1.33 \mathrm{E}-03)=$ & $1.19 \mathrm{E}-02(9.73 \mathrm{E}-04)+$ & $2.39 \mathrm{E}-04(3.10 \mathrm{E}-05)=$ & $3.10 \mathrm{E}-04(4.57 \mathrm{E}-05)$ \\
\hline & close to/on PF & $1.08 \mathrm{E}-03(5.76 \mathrm{E}-03)+$ & $1.12 \mathrm{E}-04(5.38 \mathrm{E}-06)=$ & $4.00 \mathrm{E}-02(7.08 \mathrm{E}-02)+$ & $1.15 \mathrm{E}-04(2.09 \mathrm{E}-05)=$ & $1.50 \mathrm{E}-04(8.73 \mathrm{E}-05)$ \\
\hline & feasible region & $2.04 \mathrm{E}-04(1.60 \mathrm{E}-05)+$ & $2.43 \mathrm{E}-04(5.44 \mathrm{E}-04)+$ & $2.15 \mathrm{E}-04(2.07 \mathrm{E}-05)+$ & $2.00 \mathrm{E}-04(6.98 \mathrm{E}-05)=$ & $9.99 \mathrm{E}-05(1.27 \mathrm{E}-04)$ \\
\hline \multirow{3}{*}{ ZDT4 } & infeasible region & $7.79 \mathrm{E}-04(7.08 \mathrm{E}-04)+$ & $7.23 \mathrm{E}-04(5.15 \mathrm{E}-04)=$ & $6.66 \mathrm{E}-04(4.74 \mathrm{E}-04)=$ & $7.24 \mathrm{E}-03(2.06 \mathrm{E}-02)+$ & $3.50 \mathrm{E}-04(1.81 \mathrm{E}-04)$ \\
\hline & close to/on PF & $2.28 \mathrm{E}-03(3.32 \mathrm{E}-03)+$ & 7.06E-04(1.65E-03)+ & $5.96 \mathrm{E}-04(4.87 \mathrm{E}-04)=$ & $4.76 \mathrm{E}-04(1.10 \mathrm{E}-04)=$ & $3.31 \mathrm{E}-04(7.88 \mathrm{E}-04)$ \\
\hline & feasible region & $6.91 \mathrm{E}-04(3.60 \mathrm{E}-04)+$ & $1.28 \mathrm{E}-04(2.82 \mathrm{E}-04)=$ & $5.28 \mathrm{E}-04(3.28 \mathrm{E}-04)=$ & $6.53 \mathrm{E}-04(5.46 \mathrm{E}-04)+$ & $8.33 \mathrm{E}-05(1.07 \mathrm{E}-04)$ \\
\hline \multirow{3}{*}{ DTLZ1 } & infeasible region & $1.08 \mathrm{E}+02(4.52 \mathrm{E}+01)+$ & $3.06 \mathrm{E}-03(4.15 \mathrm{E}-03)+$ & $2.49 \mathrm{E}-03(1.02 \mathrm{E}-03)+$ & $2.26 \mathrm{E}-03(1.23 \mathrm{E}-04)+$ & $2.29 \mathrm{E}-04(3.47 \mathrm{E}-04)$ \\
\hline & close to/on PF & $9.14 \mathrm{E}+01(3.66 \mathrm{E}+01)+$ & $3.98 \mathrm{E}-03(5.42 \mathrm{E}-03)+$ & $2.31 \mathrm{E}-03(2.35 \mathrm{E}-04)+$ & $2.53 \mathrm{E}-03(4.87 \mathrm{E}-05)+$ & $2.51 \mathrm{E}-04(7.92 \mathrm{E}-06)$ \\
\hline & feasible region & $1.02 \mathrm{E}+00(4.74 \mathrm{E}+01)+$ & $3.30 \mathrm{E}-02(1.55 \mathrm{E}-01)+$ & $2.29 \mathrm{E}-03(3.31 \mathrm{E}-04)+$ & $2.27 \mathrm{E}-03(4.31 \mathrm{E}-04)+$ & $1.51 \mathrm{E}-03(6.85 \mathrm{E}-03)$ \\
\hline \multirow{3}{*}{ DTLZ2 } & infeasible region & $7.28 \mathrm{E}-02(2.34 \mathrm{E}-02)+$ & $8.96 \mathrm{E}-03(6.92 \mathrm{E}-04)+$ & $8.48 \mathrm{E}-03(7.01 \mathrm{E}-04)+$ & $5.48 \mathrm{E}-03(1.24 \mathrm{E}-04)+$ & $5.74 \mathrm{E}-04(2.19 \mathrm{E}-04)$ \\
\hline & close to/on PF & $1.65 \mathrm{E}-01(7.70 \mathrm{E}-02)+$ & $6.33 \mathrm{E}-03(4.13 \mathrm{E}-04)+$ & $5.90 \mathrm{E}-03(2.28 \mathrm{E}-04)+$ & $6.66 \mathrm{E}-03(3.19 \mathrm{E}-03)+$ & $6.13 \mathrm{E}-04(6.10 \mathrm{E}-04)$ \\
\hline & feasible region & 7.17E-03(4.77E-04)+ & $9.61 \mathrm{E}-03(8.32 \mathrm{E}-04)+$ & 7.53E-03(4.51E-04)+ & $5.89 \mathrm{E}-03(1.56 \mathrm{E}-03)+$ & $3.83 \mathrm{E}-04(4.20 \mathrm{E}-04)$ \\
\hline \multirow{3}{*}{ DTLZ3 } & infeasible region & $2.43 \mathrm{E}+02(8.88 \mathrm{E}+01)+$ & $1.97 \mathrm{E}-02(4.55 \mathrm{E}-02)+$ & $8.65 \mathrm{E}-03(2.82 \mathrm{E}-03)=$ & $6.17 \mathrm{E}-03(4.97 \mathrm{E}-04)=$ & $3.36 \mathrm{E}-03(8.34 \mathrm{E}-03)$ \\
\hline & close to/on PF & $2.77 \mathrm{E}+02(1.04 \mathrm{E}+02)+$ & $2.25 \mathrm{E}-02(3.46 \mathrm{E}-02)+$ & $6.39 \mathrm{E}-03(6.53 \mathrm{E}-04)=$ & $6.57 \mathrm{E}-03(2.98 \mathrm{E}-04)=$ & $6.76 \mathrm{E}-03(3.06 \mathrm{E}-04)$ \\
\hline & feasible region & $2.91 \mathrm{E}+02(1.36 \mathrm{E}+02)+$ & $2.56 \mathrm{E}-01(6.41 \mathrm{E}-01)+$ & $7.59 \mathrm{E}-03(2.00 \mathrm{E}-03)=$ & $7.01 \mathrm{E}-03(2.03 \mathrm{E}-03)=$ & $5.79 \mathrm{E}-03(3.76 \mathrm{E}-04)$ \\
\hline \multirow{3}{*}{ DTLZ4 } & infeasible region & $4.45 \mathrm{E}-02(2.52 \mathrm{E}-02)+$ & $1.07 \mathrm{E}-02(1.19 \mathrm{E}-03)+$ & $7.61 \mathrm{E}-03(1.75 \mathrm{E}-03)=$ & $1.27 \mathrm{E}-02(2.13 \mathrm{E}-03)+$ & $7.26 \mathrm{E}-03(1.45 \mathrm{E}-02)$ \\
\hline & close to/on PF & $8.85 \mathrm{E}-02(5.39 \mathrm{E}-02)+$ & $5.90 \mathrm{E}-03(3.55 \mathrm{E}-04)=$ & $4.73 \mathrm{E}-03(1.80 \mathrm{E}-03)=$ & $1.34 \mathrm{E}-02(1.87 \mathrm{E}-03)+$ & $6.17 \mathrm{E}-03(2.01 \mathrm{E}-03)$ \\
\hline & feasible region & $7.12 \mathrm{E}-03(4.50 \mathrm{E}-04)+$ & $1.11 \mathrm{E}-02(1.30 \mathrm{E}-03)+$ & $6.93 \mathrm{E}-03(7.45 \mathrm{E}-04)=$ & $1.33 \mathrm{E}-02(3.06 \mathrm{E}-03)+$ & $1.59 \mathrm{E}-03(5.36 \mathrm{E}-03)$ \\
\hline \multirow{3}{*}{ DTLZ5 } & infeasible region & $8.83 \mathrm{E}-02(1.67 \mathrm{E}-02)+$ & $4.17 \mathrm{E}-03(2.09 \mathrm{E}-04)=$ & $1.13 \mathrm{E}-02(2.80 \mathrm{E}-03)+$ & $3.54 \mathrm{E}-03(5.50 \mathrm{E}-05)=$ & $3.81 \mathrm{E}-03(2.10 \mathrm{E}-03)$ \\
\hline & close to/on PF & $2.01 \mathrm{E}-02(8.03 \mathrm{E}-02)+$ & $4.03 \mathrm{E}-03(3.69 \mathrm{E}-04)=$ & $3.95 \mathrm{E}-03(9.76 \mathrm{E}-05)=$ & $3.35 \mathrm{E}-03(3.04 \mathrm{E}-05)=$ & $2.76 \mathrm{E}-03(4.88 \mathrm{E}-04)$ \\
\hline & feasible region & $4.21 \mathrm{E}-03(2.27 \mathrm{E}-04)+$ & $4.15 \mathrm{E}-03(2.34 \mathrm{E}-04)=$ & $4.16 \mathrm{E}-03(1.41 \mathrm{E}-04)=$ & $4.22 \mathrm{E}-03(3.89 \mathrm{E}-05)=$ & $4.26 \mathrm{E}-03(2.85 \mathrm{E}-04)$ \\
\hline \multirow{3}{*}{ DTLZ6 } & infeasible region & $3.29 \mathrm{E}+00(1.73 \mathrm{E}+00)+$ & $4.77 \mathrm{E}-02(1.34 \mathrm{E}-02)-$ & $4.18 \mathrm{E}-02(7.94 \mathrm{E}-03)-$ & $4.07 \mathrm{E}-02(2.96 \mathrm{E}-02)-$ & $1.83 \mathrm{E}-01(1.38 \mathrm{E}-01)$ \\
\hline & close to/on PF & $3.48 \mathrm{E}+00(1.81 \mathrm{E}+00)+$ & $4.57 \mathrm{E}-02(1.51 \mathrm{E}-02)-$ & $3.94 \mathrm{E}-02(1.22 \mathrm{E}-02)-$ & $1.84 \mathrm{E}-02(1.70 \mathrm{E}-02)-$ & $5.77 \mathrm{E}-02(1.39 \mathrm{E}-02)$ \\
\hline & feasible region & $3.80 \mathrm{E}+00(1.56 \mathrm{E}+00)+$ & $4.82 \mathrm{E}-02(9.72 \mathrm{E}-03)=$ & $4.05 \mathrm{E}-02(9.33 \mathrm{E}-03)=$ & $2.84 \mathrm{E}-02(2.18 \mathrm{E}-02)-$ & $4.82 \mathrm{E}-02(1.52 \mathrm{E}-02)$ \\
\hline$+1=1-$ & & $14 / 14 / 2$ & $12 / 16 / 2$ & $12 / 16 / 2$ & $14 / 13 / 3$ & \\
\hline
\end{tabular}

,$+=$ and - indicate Ra-NSGA-II performs significantly better than, equiv-

alently to, and worse than the corresponding algorithm, respectively. 
Table 3: Mean and standard deviation SP values on ZDT and 3-objective DTLZ

\begin{tabular}{|c|c|c|c|c|c|c|}
\hline Instance & $g$ & g-NSGA-II & r-NSGA-II & p-NSGA-II & WASF-GA & Ra-NSGA-II \\
\hline \multirow{3}{*}{ ZDT1 } & infeasible region & $3.70 \mathrm{E}-03(2.81 \mathrm{E}-04)=$ & $1.73 \mathrm{E}-03(7.72 \mathrm{E}-04)=$ & $4.30 \mathrm{E}-03(3.81 \mathrm{E}-04)+$ & $4.49 \mathrm{E}-03(1.77 \mathrm{E}-03)+$ & $1.33 \mathrm{E}-03(1.09 \mathrm{E}-03)$ \\
\hline & close to/on PF & $5.52 \mathrm{E}-05(6.95 \mathrm{E}-06)=$ & $2.87 \mathrm{E}-04(3.97 \mathrm{E}-04)=$ & $5.52 \mathrm{E}-04(3.99 \mathrm{E}-05)+$ & $5.88 \mathrm{E}-03(5.93 \mathrm{E}-02)+$ & $1.65 \mathrm{E}-04(2.96 \mathrm{E}-04)$ \\
\hline & feasible region & $2.31 \mathrm{E}-03(1.92 \mathrm{E}-04)=$ & $3.74 \mathrm{E}-03(2.48 \mathrm{E}-03)=$ & $3.09 \mathrm{E}-03(2.64 \mathrm{E}-04)+$ & $2.78 \mathrm{E}-03(1.55 \mathrm{E}-04)+$ & $6.30 \mathrm{E}-04(8.39 \mathrm{E}-04)$ \\
\hline \multirow{3}{*}{ ZDT2 } & infeasible region & $5.77 \mathrm{E}-03(6.87 \mathrm{E}-04)-$ & $4.16 \mathrm{E}-03(1.12 \mathrm{E}-03)-$ & $4.63 \mathrm{E}-03(4.20 \mathrm{E}-04)-$ & $7.42 \mathrm{E}-03(2.54 \mathrm{E}-03)=$ & $2.01 \mathrm{E}-02(1.64 \mathrm{E}-02)$ \\
\hline & close to/on PF & $1.68 \mathrm{E}-03(3.70 \mathrm{E}-03)+$ & $8.44 \mathrm{E}-05(2.60 \mathrm{E}-04)+$ & $5.14 \mathrm{E}-04(5.13 \mathrm{E}-05)+$ & $1.53 \mathrm{E}-02(9.92 \mathrm{E}-03)+$ & $5.71 \mathrm{E}-06(1.87 \mathrm{E}-05)$ \\
\hline & feasible region & $5.59 \mathrm{E}-04(5.35 \mathrm{E}-05)-$ & $2.78 \mathrm{E}-03(2.43 \mathrm{E}-03)+$ & $4.97 \mathrm{E}-04(5.37 \mathrm{E}-05)-$ & $1.05 \mathrm{E}-02(8.90 \mathrm{E}-03)+$ & $1.06 \mathrm{E}-03(3.37 \mathrm{E}-03)$ \\
\hline \multirow{3}{*}{ ZDT3 } & infeasible region & $7.30 \mathrm{E}-03(1.75 \mathrm{E}-03)+$ & $6.93 \mathrm{E}-03(7.21 \mathrm{E}-03)+$ & 4. $63 \mathrm{E}-03(4.20 \mathrm{E}-04)+$ & $5.03 \mathrm{E}-03(2.95 \mathrm{E}-03)+$ & $4.36 \mathrm{E}-03(7.59 \mathrm{E}-04)$ \\
\hline & close to/on PF & $2.22 \mathrm{E}-04(4.31 \mathrm{E}-04)+$ & $2.63 \mathrm{E}-04(5.24 \mathrm{E}-04)+$ & $8.53 \mathrm{E}-04(5.02 \mathrm{E}-04)=$ & $2.85 \mathrm{E}-03(1.03 \mathrm{E}-02)+$ & $2.70 \mathrm{E}-05(6.80 \mathrm{E}-05)$ \\
\hline & feasible region & $1.63 \mathrm{E}-03(1.20 \mathrm{E}-04)+$ & $1.01 \mathrm{E}-02(1.37 \mathrm{E}-02)+$ & $1.49 \mathrm{E}-03(1.40 \mathrm{E}-04)+$ & $3.75 \mathrm{E}-03(3.95 \mathrm{E}-4)+$ & $7.60 \mathrm{E}-04(8.11 \mathrm{E}-03)$ \\
\hline \multirow{3}{*}{ ZDT4 } & infeasible region & $3.84 \mathrm{E}-03(7.51 \mathrm{E}-04)-$ & $3.96 \mathrm{E}-03(1.39 \mathrm{E}-03)-$ & $4.28 \mathrm{E}-03(2.88 \mathrm{E}-04)-$ & $7.45 \mathrm{E}-02(2.03 \mathrm{E}-01)=$ & $3.20 \mathrm{E}-02(6.14 \mathrm{E}-02)$ \\
\hline & close to/on PF & $6.72 \mathrm{E}-04(5.13 \mathrm{E}-04)+$ & $2.67 \mathrm{E}-03(1.35 \mathrm{E}-02)+$ & $5.27 \mathrm{E}-04(4.80 \mathrm{E}-05)+$ & $2.80 \mathrm{E}-02(7.10 \mathrm{E}-03)+$ & $7.85 \mathrm{E}-05(2.13 \mathrm{E}-04)$ \\
\hline & feasible region & $2.27 \mathrm{E}-03(2.12 \mathrm{E}-04)-$ & $1.22 \mathrm{E}-01(2.94 \mathrm{E}-01)+$ & $3.07 \mathrm{E}-03(3.24 \mathrm{E}-04)-$ & $2.04 \mathrm{E}-02(4.88 \mathrm{E}-03)-$ & $6.50 \mathrm{E}-02(9.45 \mathrm{E}-02)$ \\
\hline \multirow{3}{*}{ DTLZ1 } & infeasible region & $7.48 \mathrm{E}+00(3.96 \mathrm{E}+00)+$ & $2.25 \mathrm{E}-02(2.73 \mathrm{E}-03)+$ & $2.38 \mathrm{E}-02(1.05 \mathrm{E}-02)+$ & $4.73 \mathrm{E}-02(2.28 \mathrm{E}-04)+$ & $1.70 \mathrm{E}-02(3.29 \mathrm{E}-03)$ \\
\hline & close to/on PF & $5.67 \mathrm{E}+00(2.77 \mathrm{E}+00)+$ & $2.23 \mathrm{E}-02(2.82 \mathrm{E}-03)+$ & $2.16 \mathrm{E}-02(1.73 \mathrm{E}-03)+$ & $6.21 \mathrm{E}-02(3.88 \mathrm{E}-03)+$ & $2.93 \mathrm{E}-07(2.16 \mathrm{E}-07)$ \\
\hline & feasible region & $6.30 \mathrm{E}+00(3.58 \mathrm{E}+00)+$ & $3.27 \mathrm{E}-01(1.55 \mathrm{E}+00)+$ & $2.20 \mathrm{E}-02(1.92 \mathrm{E}-03)+$ & $2.80 \mathrm{E}-02(1.31 \mathrm{E}-04)+$ & $1.70 \mathrm{E}-02(3.29 \mathrm{E}-03)$ \\
\hline \multirow{3}{*}{ DTLZ2 } & infeasible region & $6.34 \mathrm{E}-02(1.23 \mathrm{E}-02)+$ & $3.80 \mathrm{E}-02(4.31 \mathrm{E}-03)=$ & $3.62 \mathrm{E}-02(2.98 \mathrm{E}-03)=$ & $5.80 \mathrm{E}-02(1.35 \mathrm{E}-03)+$ & $3.13 \mathrm{E}-02(1.97 \mathrm{E}-02)$ \\
\hline & close to/on PF & $3.72 \mathrm{E}-02(2.03 \mathrm{E}-02)+$ & $7.23 \mathrm{E}-04(2.66 \mathrm{E}-04)+$ & $4.05 \mathrm{E}-03(3.45 \mathrm{E}-04)+$ & $6.54 \mathrm{E}-02(1.96 \mathrm{E}-02)+$ & $1.91 \mathrm{E}-04(8.14 \mathrm{E}-04)$ \\
\hline & feasible region & $3.59 \mathrm{E}-02(3.71 \mathrm{E}-03)+$ & $1.71 \mathrm{E}-02(3.62 \mathrm{E}-03)+$ & $2.46 \mathrm{E}-02(2.10 \mathrm{E}-03)+$ & $6.00 \mathrm{E}-02(9.02 \mathrm{E}-03)+$ & $3.57 \mathrm{E}-03(8.13 \mathrm{E}-03)$ \\
\hline \multirow{3}{*}{ DTLZ3 } & infeasible region & $1.63 \mathrm{E}+01(1.11 \mathrm{E}+01)+$ & $3.80 \mathrm{E}-02(4.31 \mathrm{E}-03)+$ & $3.63 \mathrm{E}-02(3.07 \mathrm{E}-03)+$ & $5.86 \mathrm{E}-02(1.36 \mathrm{E}-03)+$ & $6.35 \mathrm{E}-03(1.29 \mathrm{E}-02)$ \\
\hline & close to/on PF & $1.69 \mathrm{E}+01(8.69 \mathrm{E}+00)+$ & $1.50 \mathrm{E}-01(2.72 \mathrm{E}-01)+$ & $4.13 \mathrm{E}-03(4.19 \mathrm{E}-04)+$ & $1.41 \mathrm{E}-01(6.07 \mathrm{E}-03)+$ & $6.09 \mathrm{E}-06(6.55 \mathrm{E}-06)$ \\
\hline & feasible region & $2.00 \mathrm{E}+01(1.40 \mathrm{E}+01)+$ & $1.11 \mathrm{E}+00(2.59 \mathrm{E}+00)+$ & $2.50 \mathrm{E}-02(2.71 \mathrm{E}-03)+$ & $4.06 \mathrm{E}-02(1.05 \mathrm{E}-03)+$ & $4.80 \mathrm{E}-03(2.06 \mathrm{E}-03)$ \\
\hline \multirow{3}{*}{ DTLZ4 } & infeasible region & $5.54 \mathrm{E}-02(8.49 \mathrm{E}-03)+$ & $5.62 \mathrm{E}-02(3.83 \mathrm{E}-03)=$ & $3.31 \mathrm{E}-02(1.14 \mathrm{E}-02)+$ & $1.12 \mathrm{E}-01(2.36 \mathrm{E}-02)+$ & $2.56 \mathrm{E}-02(2.63 \mathrm{E}-03)$ \\
\hline & close to/on PF & $1.78 \mathrm{E}-02(1.39 \mathrm{E}-02)+$ & $3.61 \mathrm{E}-03(5.29 \mathrm{E}-04)+$ & $2.50 \mathrm{E}-03(1.96 \mathrm{E}-03)+$ & $1.16 \mathrm{E}-01(1.92 \mathrm{E}-02)+$ & $3.50 \mathrm{E}-05(3.84 \mathrm{E}-05)$ \\
\hline & feasible region & $3.64 \mathrm{E}-02(3.93 \mathrm{E}-03)+$ & $3.71 \mathrm{E}-02(4.86 \mathrm{E}-03)+$ & $2.06 \mathrm{E}-02(9.53 \mathrm{E}-03)+$ & $1.21 \mathrm{E}-01(2.68 \mathrm{E}-02)+$ & $6.42 \mathrm{E}-03(4.33 \mathrm{E}-02)$ \\
\hline \multirow{3}{*}{ DTLZ5 } & infeasible region & $1.51 \mathrm{E}-02(8.36 \mathrm{E}-03)-$ & $6.27 \mathrm{E}-03(6.88 \mathrm{E}-03)-$ & $2.88 \mathrm{E}-03(3.41 \mathrm{E}-04)-$ & $1.31 \mathrm{E}-02(9.94 \mathrm{E}-05)-$ & $5.09 \mathrm{E}-02(4.50 \mathrm{E}-02)$ \\
\hline & close to/on PF & $6.02 \mathrm{E}-03(1.64 \mathrm{E}-02)+$ & $4.21 \mathrm{E}-04(6.09 \mathrm{E}-04)+$ & $6.90 \mathrm{E}-04(4.96 \mathrm{E}-05)+$ & $1.74 \mathrm{E}-01(5.46 \mathrm{E}-03)+$ & $1.07 \mathrm{E}-05(2.14 \mathrm{E}-05)$ \\
\hline & feasible region & $6.10 \mathrm{E}-03(5.72 \mathrm{E}-04)-$ & $5.02 \mathrm{E}-03(3.13 \mathrm{E}-03)-$ & $3.95 \mathrm{E}-03(3.27 \mathrm{E}-04)-$ & $5.03 \mathrm{E}-02(3.19 \mathrm{E}-02)+$ & $9.09 \mathrm{E}-03(9.05 \mathrm{E}-04)$ \\
\hline \multirow{3}{*}{ DTLZ6 } & infeasible region & $2.60 \mathrm{E}-01(1.24 \mathrm{E}-01)+$ & $1.75 \mathrm{E}-02(2.34 \mathrm{E}-03)-$ & $5.53 \mathrm{E}-03(2.50 \mathrm{E}-03)-$ & $2.30 \mathrm{E}-02(6.32 \mathrm{E}-03)-$ & $3.56 \mathrm{E}-02(2.94 \mathrm{E}-02)$ \\
\hline & close to/on PF & $2.10 \mathrm{E}-01(1.28 \mathrm{E}-01)+$ & $2.44 \mathrm{E}-03(5.88 \mathrm{E}-04)+$ & $2.31 \mathrm{E}-03(4.17 \mathrm{E}-04)+$ & $1.71 \mathrm{E}-01(5.81 \mathrm{E}-03)+$ & $7.83 \mathrm{E}-04(1.81 \mathrm{E}-04)$ \\
\hline & feasible region & $3.08 \mathrm{E}-01(1.16 \mathrm{E}-01)+$ & $1.56 \mathrm{E}-02(3.08 \mathrm{E}-03)-$ & $8.72 \mathrm{E}-03(8.60 \mathrm{E}-04)-$ & $1.30 \mathrm{E}-02(4.69 \mathrm{E}-03)=$ & $2.51 \mathrm{E}-02(1.89 \mathrm{E}-02)$ \\
\hline$+/=/$ & & $21 / 3 / 6$ & $\begin{array}{l}19 / 5 / 6 \\
\end{array}$ & $20 / 2 / 8$ & $24 / 3 / 3$ & \\
\hline
\end{tabular}

,$+=$ and - indicate Ra-NSGA-II performs significantly better than, equiv-

alently to, and worse than the corresponding algorithm, respectively. 


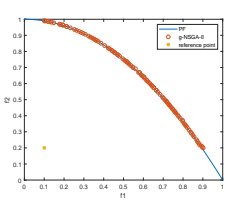

(a) g-NSGA-II

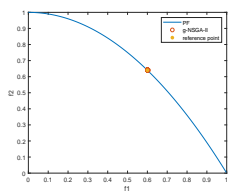

(f) g-NSGA-II

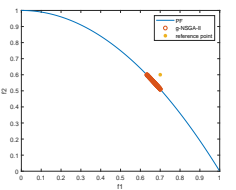

(k) g-NSGA-II

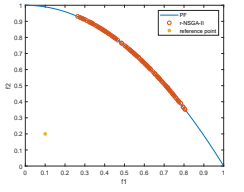

(b) r-NSGA-II

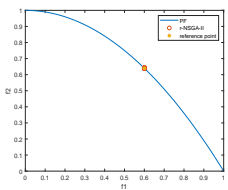

(g) r-NSGA-II

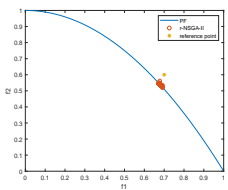

(l) r-NSGA-II

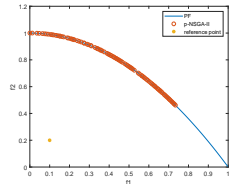

(c) p-NSGA-II

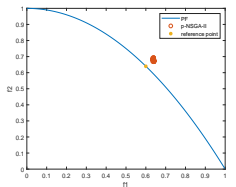

(h) p-NSGA-II

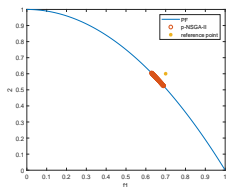

(m) p-NSGA-II

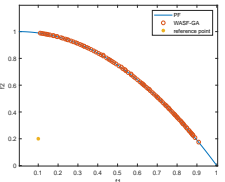

(d) WASF-GA

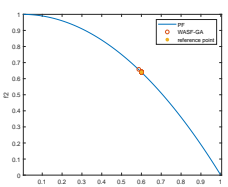

(i) WASF-GA

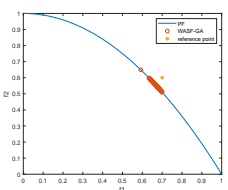

(n) WASF-GA

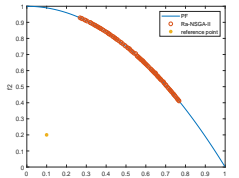

(e) Ra-NSGA-II

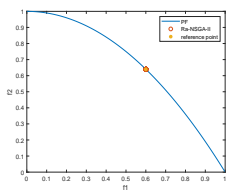

(j) Ra-NSGA-II

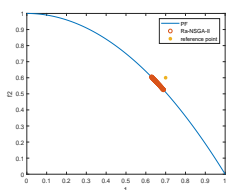

(o) Ra-NSGA-II

Figure 11: Optimal solutions on ZDT2 with reference point in the infeasible region: (a)-(e); on/close to the true PF: (f)-(j); and in the feasible region: (k)-(o). 


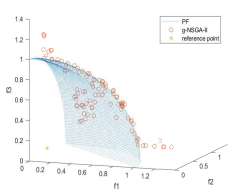

(a) g-NSGA-II

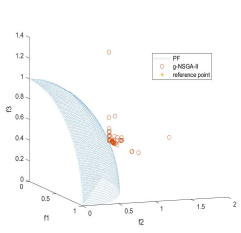

(f) g-NSGA-II

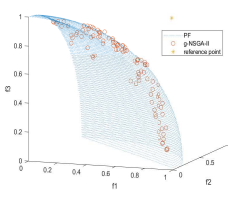

(k) g-NSGA-II

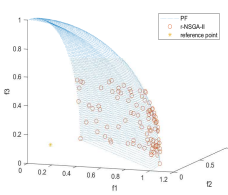

(b) r-NSGA-II

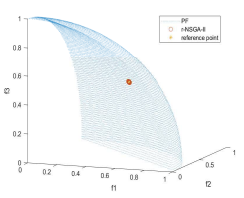

(g) r-NSGA-II

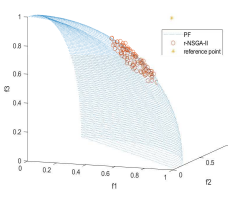

(l) r-NSGA-II

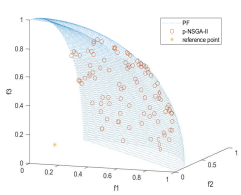

(c) p-NSGA-II

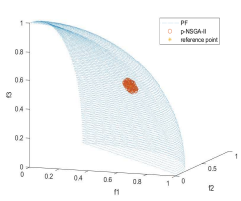

(h) p-NSGA-II

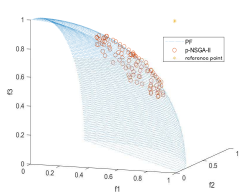

(m) p-NSGA-II

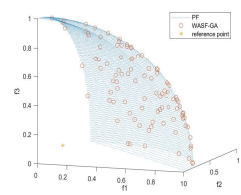

(d) WASF-GA

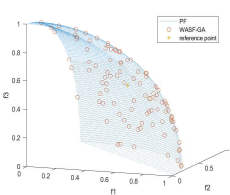

(i) WASF-GA

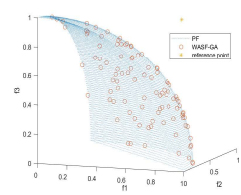

(n) WASF-GA (e) Ra-NSGA-II
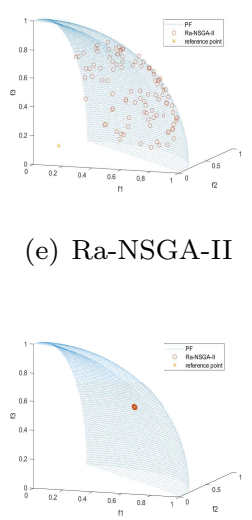

(j) Ra-NSGA-II

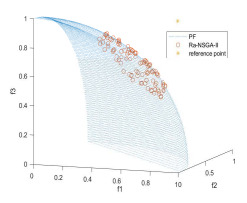

(o) Ra-NSGA-II

Figure 12: Optimal solutions on DTLZ2 with reference point in the infeasible region: (a)-(e); on/close to the true PF: (f)-(j); and in the feasible region: (k)-(o). 


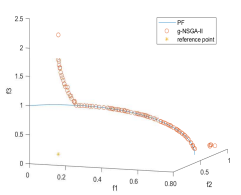

(a) g-NSGA-II

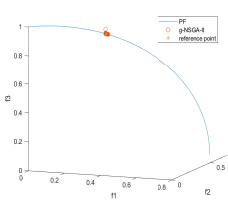

(f) g-NSGA-II

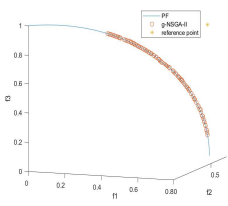

(k) g-NSGA-II

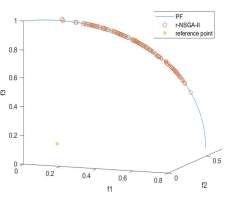

(b) r-NSGA-II

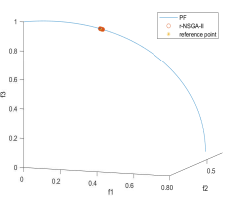

(g) r-NSGA-II

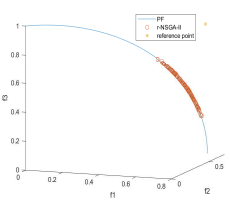

(1) r-NSGA-II

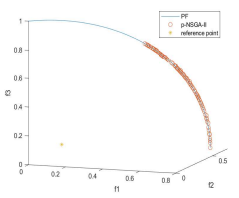

(c) p-NSGA-II

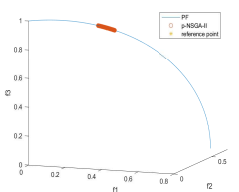

(h) p-NSGA-II

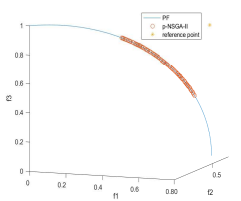

(m) p-NSGA-II

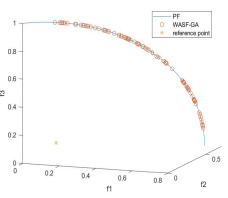

(d) WASF-GA

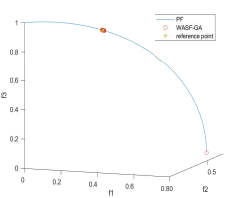

(i) WASF-GA

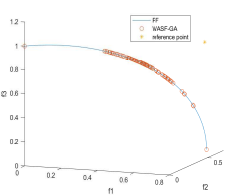

(n) WASF-GA (e) Ra-NSGA-II
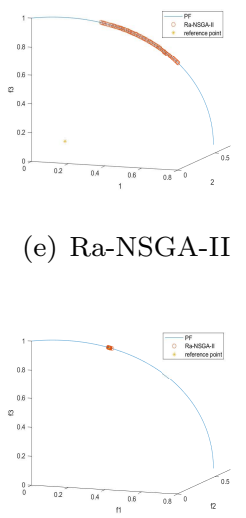

(j) Ra-NSGA-II

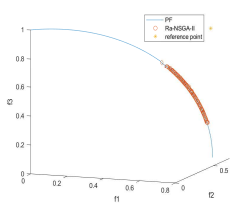

(o) Ra-NSGA-II

Figure 13: Optimal solutions on DTLZ5 with reference point in the infeasible region: (a)-(e); on/close to the true PF: (f)-(j); and in the feasible region: (k)-(o). 
order to make the experimental results more comparative, we set the parameters of different algorithms in advance to approximate a similar ROI. Reference points and some essential parameters in different algorithms shown in Table 1 .

For each instance, the three reference points from top to bottom are in the infeasible region, close to/on PF and in the feasible region. The statistical results based on GD and SP values of the obtained solutions by the three algorithms on the ZDT and 3-objective DTLZ are shown in Table 2 and Table 3, where the best mean and standard deviation are colored in dark gray and the second best are lighlighted in light gray. The Wilcoxon's rank sum test 41 at a $5 \%$ significance level is conducted to test the significance of differences between RaNSGA-II and comparison algorithms, with the standard Bonferroni correction [42] to deal with the problem of the higher probability of Type I errors in multiple comparisons.

As can be seen in Table 2, all five algorithms converged well on the ZDT test suite. Clearly, the average GD values obtained by Ra-NSGA-II are smaller than the other three algorithms on ZDT1, ZDT4, DTLZ1 adn DTLZ2 no matter where the reference point is. However, Ra-NSGA-II remains one of the excellent performance algorithms on the other ZDT and DTLZ problems though its GD values are not the smallest on some individual problems. There is no exponential difference between Ra-NSGA-II and the best performing algorithm. Specially, g-NSGA-II failed to converge into the true PF on DTLZ1, DTLZ3 and DTLZ6. Ra-NSGA-II, p-NSGA-II and WASF-GA are three best algorithms on DTLZ. Among them, Ra-NSGA-II has the best GD values on DTLZ1 and DTLZ2, and on DTLZ3 and DTLZ4 when reference point not on the PF. The statistical test results showed in Table 2 indicate that Ra-NSGA-II significantly outperform the other algorithms on the majority of cases in terms of GD metric values.

From Table 3 we can see that the solution set obtained by Ra-NSGA-II had the smallest SP values on the three-objective DTLZ1-4, and it had the best uniform distribution on most ZDT problems. It is worth noticing that p-NSGA-

$395 \mathrm{II}$ is the second best algorithm on distribution and even has the smallest SP on most DTLZ5 and DTLZ6 problems. The statistical results in Table 3 shows that 
Table 4: Reference point and parameters used in many-objective problems, $(\sim / \sim / \sim)$ represents three numbers on $(5$-obj/8-obj/10-obj)

\begin{tabular}{cccccc}
\hline \multirow{2}{*}{ Instance } & & reference point & $\delta$ in r-NSGA-II & $d_{p}$ in p-NSGA-II & $\delta$ in Ra-NSGA-II \\
\hline \multirow{2}{*}{ DTLZ1 } & infeasible region & $(0.04,0.04, \cdots)$ & 0.7 & 0.2 & $0.7 / 0.75 / 0.8$ \\
& feasible region & $(0.15,0.15, \cdots)$ & 0.3 & 0.08 & $0.3 / 0.25 / 0.2$ \\
\hline \multirow{2}{*}{ DTLZ2-4 } & infeasible region & $(0.2,0.2, \cdots)$ & 0.7 & 0.55 & 0.7 \\
& feasible region & $(0.35,0.35, \cdots)$ & 0.7 & 0.55 & $0.7 / 0.7 / 0.75$ \\
\hline \multirow{2}{*}{ DTLZ5-6 } & infeasible region & $(0.2,0.2, \cdots)$ & 0.65 & 0.3 & 0.65 \\
& feasible region & $(0.35,0.35, \cdots)$ & 0.3 & 0.1 & 0.3 \\
\hline
\end{tabular}

Ra-NSGA-II has significant superiority over other algorithms on most ZDT and 3-objective DTLZ test problems. Compared with other algorithms except pNSGA-II, Ra-NSGA-II has a significant advantage in terms of SP metric values.

We randomly extracted one experimental result from 30 independent experiments. Fig 11, Fig 12 and Fig 13 shows the obtained solutions on ZDT2, DTLZ2 and DTLZ5. g-NSGA-II shows both convergence and distribution on ZDT2 while can not converge to true PF very well on 3-obj DTLZ2 and DTLZ5. p-NSGA-II shows its drawback when the reference point close to or on the PF. The solution set obtained by p-NSGA-II can converge neither to the true PF (Fig 11(h)) nor the ROI area in theory (Fig 12(h), Fig 13(h)) like other algorithms. WASF-GA did not perform well on DTLZ2 as it just converge to PF but not to the DM's satisfied region. Comparing Fig 12 (f) and (i), (k) and (n), we can see that WASF-GA did not obtain the real ROI solutions since it has the same ROI definition as g-NSGA-II. On the other hand, WASF-GA had poor distribution on DTLZ5, which can be seen in Fig 13 , Ra-NSGA-II performed very well on three problems regardless of convergence or distribution.

\subsection{Experiment on many-objective problems}

To demonstrate the scalability of dealing with many-objective optimization problems, we conducted comparative experiments on DTLZ with 5, 8 and 10 objectives with the number of generation set as 1000, 1500 and 2000 respectively. The reference points and parameter setting in different algorithms were given in Table 4 Table 5 and Table 6 presents the average GD and SP values obtained by 
Table 5: Mean and standard deviation GD values on many-objective DTLZ

\begin{tabular}{|c|c|c|c|c|c|c|c|}
\hline Instance & $\mathrm{M}$ & $g$ & g-NSGA-II & r-NSGA-II & p-NSGA-II & WASF-GA & Ra-NSGA-II \\
\hline \multirow{6}{*}{ DTLZ1 } & \multirow{2}{*}{5} & infeasible & $3.11 \mathrm{E}+02(1.71 \mathrm{E}+01)+$ & $4.22 \mathrm{E}+01(1.32 \mathrm{E}+01)+$ & $2.46 \mathrm{E}-02(1.46 \mathrm{E}-03)=$ & $2.45 \mathrm{E}-02(2.39 \mathrm{E}-04)=$ & $1.52 \mathrm{E}-02(6.69 \mathrm{E}-02)$ \\
\hline & & feasible & $3.21 \mathrm{E}+02(1.37 \mathrm{E}+01)+$ & $1.38 \mathrm{E}+01(3.04 \mathrm{E}+00)+$ & $2.79 \mathrm{E}-02(4.65 \mathrm{E}-04)+$ & $2.04 \mathrm{E}-02(4.74 \mathrm{E}-04)+$ & $8.56 \mathrm{E}-03(2.96 \mathrm{E}-03)$ \\
\hline & \multirow[b]{2}{*}{8} & infeasible & $3.50 \mathrm{E}+02(5.85 \mathrm{E}+00)+$ & $8.15 \mathrm{E}+01(8.71 \mathrm{E}+00)+$ & $9.75 \mathrm{E}-02(3.07 \mathrm{E}-03)=$ & $6.20 \mathrm{E}-02(7.66 \mathrm{E}-04)-$ & $7.35 \mathrm{E}-02(3.82 \mathrm{E}-02)$ \\
\hline & & feasible & $3.48 \mathrm{E}+02(9.48 \mathrm{E}+00)+$ & $1.60 \mathrm{E}+01(1.88 \mathrm{E}+00)+$ & $6.90 \mathrm{E}-02(1.19 \mathrm{E}-03)=$ & $4.19 \mathrm{E}-02(1.56 \mathrm{E}-03)-$ & $5.63 \mathrm{E}-02(4.93 \mathrm{E}-02)$ \\
\hline & \multirow{2}{*}{10} & $\begin{array}{c}\text { infeasible } \\
\text {. }\end{array}$ & $3.60 \mathrm{E}+02(5.42 \mathrm{E}+00)+$ & $8.45 \mathrm{E}+01(1.63 \mathrm{E}+01)+$ & $1.11 \mathrm{E}-01(2.68 \mathrm{E}-03)=$ & $8.28 \mathrm{E}-02(6.03 \mathrm{E}-04)-$ & $1.21 \mathrm{E}-01(5.97 \mathrm{E}-01)$ \\
\hline & & feasible & $3.58 \mathrm{E}+02(8.22 \mathrm{E}+00)+$ & $1.47 \mathrm{E}+01(1.86 \mathrm{E}+00)+$ & $8.85 \mathrm{E}-02(2.10 \mathrm{E}-03)-$ & $4.27 \mathrm{E}-02(4.15 \mathrm{E}-03)-$ & $3.90 \mathrm{E}-01(4.53 \mathrm{E}-01)$ \\
\hline \multirow{6}{*}{ DTLZ2 } & \multirow{2}{*}{5} & infeasible & $1.83 \mathrm{E}+00(7.28 \mathrm{E}-02)+$ & $8.95 \mathrm{E}-02(4.94 \mathrm{E}-03)+$ & $8.42 \mathrm{E}-02(2.00 \mathrm{E}-03)+$ & $7.33 \mathrm{E}-02(1.18 \mathrm{E}-03)+$ & $1.89 \mathrm{E}-02(2.45 \mathrm{E}-03)$ \\
\hline & & feasible & $2.04 \mathrm{E}+00(6.06 \mathrm{E}-02)+$ & $8.57 \mathrm{E}-02(3.64 \mathrm{E}-03)+$ & $8.60 \mathrm{E}-02(1.95 \mathrm{E}-03)+$ & $7.31 \mathrm{E}-02(1.43 \mathrm{E}-03)+$ & $2.95 \mathrm{E}-02(1.97 \mathrm{E}-03)$ \\
\hline & \multirow[b]{2}{*}{8} & $\begin{array}{c}\text { infeasible } \\
\text {. }\end{array}$ & $2.35 \mathrm{E}+00(4.63 \mathrm{E}-02)+$ & $1.88 \mathrm{E}-01(3.64 \mathrm{E}-03)+$ & $1.94 \mathrm{E}-01(2.93 \mathrm{E}-03)+$ & $1.06 \mathrm{E}-01(4.70 \mathrm{E}-03)+$ & $5.05 \mathrm{E}-02(1.52 \mathrm{E}-03)$ \\
\hline & & feasible & $2.36 \mathrm{E}+00(2.94 \mathrm{E}-02)+$ & $2.15 \mathrm{E}-01(1.18 \mathrm{E}-02)+$ & $1.91 \mathrm{E}-01(3.78 \mathrm{E}-03)+$ & $1.96 \mathrm{E}-01(2.85 \mathrm{E}-03)+$ & $5.78 \mathrm{E}-02(3.22 \mathrm{E}-03)$ \\
\hline & \multirow{2}{*}{10} & infeasible & $2.42 \mathrm{E}+00(1.41 \mathrm{E}-02)+$ & $2.51 \mathrm{E}-01(3.21 \mathrm{E}-03)+$ & $2.60 \mathrm{E}-01(3.18 \mathrm{E}-03)+$ & $1.42 \mathrm{E}-01(1.32 \mathrm{E}-02)+$ & $5.36 \mathrm{E}-02(4.97 \mathrm{E}-03)$ \\
\hline & & feasible & $2.46 \mathrm{E}+00(2.45 \mathrm{E}-02)+$ & $3.61 \mathrm{E}-01(1.36 \mathrm{E}-02)+$ & $2.58 \mathrm{E}-01(4.87 \mathrm{E}-03)+$ & $2.69 \mathrm{E}-01(3.74 \mathrm{E}-03)+$ & $2.88 \mathrm{E}-02(1.85 \mathrm{E}-03)$ \\
\hline \multirow{6}{*}{ DTLZ3 } & \multirow[b]{2}{*}{5} & infeasible & $1.41 \mathrm{E}+03(6.87 \mathrm{E}+01)+$ & $1.89 \mathrm{E}+02(2.07 \mathrm{E}+01)+$ & $8.20 \mathrm{E}-02(3.66 \mathrm{E}-03)+$ & $7.22 \mathrm{E}-02(1.33 \mathrm{E}-03)+$ & $9.45 \mathrm{E}-03(1.88 \mathrm{E}-02)$ \\
\hline & & feasible & $1.39 \mathrm{E}+03(7.30 \mathrm{E}+01)+$ & $1.86 \mathrm{E}+02(4.10 \mathrm{E}+01)+$ & $8.15 \mathrm{E}-02(1.85 \mathrm{E}-03)+$ & 7.45E-02(1.13E-03)+ & $2.60 \mathrm{E}-02(7.24 \mathrm{E}-02)$ \\
\hline & \multirow[b]{2}{*}{8} & infeasible & $1.78 \mathrm{E}+03(4.37 \mathrm{E}+01)+$ & $2.94 \mathrm{E}+02(4.42 \mathrm{E}+01)+$ & $1.89 \mathrm{E}-01(2.62 \mathrm{E}-03)+$ & $1.38 \mathrm{E}-01(9.93 \mathrm{E}-03)+$ & $3.70 \mathrm{E}-02(2.82 \mathrm{E}-02)$ \\
\hline & & feasible & $1.77 \mathrm{E}+03(5.06 \mathrm{E}+01)+$ & $3.03 \mathrm{E}+02(3.01 \mathrm{E}+01)+$ & 1.90E-01(3.07E-03)+ & $1.97 \mathrm{E}-01(2.31 \mathrm{E}-03)+$ & $2.76 \mathrm{E}-02(2.28 \mathrm{E}-02)$ \\
\hline & \multirow{2}{*}{10} & infeasible & $1.87 \mathrm{E}+03(3.90 \mathrm{E}+01)+$ & $3.96 \mathrm{E}+02(8.43 \mathrm{E}+01)+$ & $2.57 \mathrm{E}-01(4.46 \mathrm{E}-03)+$ & $1.83 \mathrm{E}-01(1.07 \mathrm{E}-02)+$ & $2.80 \mathrm{E}-02(1.52 \mathrm{E}-02)$ \\
\hline & & feasible & $1.90 \mathrm{E}+03(3.34 \mathrm{E}+01)+$ & $4.14 \mathrm{E}+02(6.24 \mathrm{E}+01)+$ & $2.58 \mathrm{E}-01(2.89 \mathrm{E}-03)+$ & $2.69 \mathrm{E}-01(6.75 \mathrm{E}-03)+$ & $4.19 \mathrm{E}-02(2.26 \mathrm{E}-02)$ \\
\hline \multirow{6}{*}{ DTLZ4 } & \multirow{2}{*}{5} & infeasible & $1.86 \mathrm{E}+00(1.21 \mathrm{E}-01)+$ & $8.71 \mathrm{E}-02(4.20 \mathrm{E}-03)+$ & $8.51 \mathrm{E}-02(4.15 \mathrm{E}-03)+$ & $7.03 \mathrm{E}-02(1.45 \mathrm{E}-03)+$ & $7.18 \mathrm{E}-03(2.12 \mathrm{E}-03)$ \\
\hline & & feasible & $1.90 \mathrm{E}+00(1.12 \mathrm{E}-01)+$ & $9.81 \mathrm{E}-02(4.60 \mathrm{E}-03)+$ & $8.74 \mathrm{E}-02(6.16 \mathrm{E}-03)+$ & $7.09 \mathrm{E}-02(3.60 \mathrm{E}-03)+$ & $7.18 \mathrm{E}-03(1.82 \mathrm{E}-03)$ \\
\hline & \multirow[b]{2}{*}{8} & infeasible & $2.35 \mathrm{E}+00(2.37 \mathrm{E}-02)+$ & $2.08 \mathrm{E}-01(6.66 \mathrm{E}-03)+$ & $1.88 \mathrm{E}-01(2.81 \mathrm{E}-03)+$ & $1.36 \mathrm{E}-01(1.91 \mathrm{E}-02)+$ & $1.82 \mathrm{E}-02(4.37 \mathrm{E}-02)$ \\
\hline & & feasible & $2.36 \mathrm{E}+00(1.70 \mathrm{E}-02)+$ & $5.09 \mathrm{E}-01(3.82 \mathrm{E}-02)+$ & $1.91 \mathrm{E}-01(3.22 \mathrm{E}-03)+$ & $1.97 \mathrm{E}-01(3.04 \mathrm{E}-03)+$ & $1.68 \mathrm{E}-02(1.51 \mathrm{E}-02)$ \\
\hline & \multirow{2}{*}{10} & infeasible & $2.41 \mathrm{E}+00(1.74 \mathrm{E}-02)+$ & $3.03 \mathrm{E}-01(1.24 \mathrm{E}-02)+$ & $2.72 \mathrm{E}-01(1.93 \mathrm{E}-02)+$ & $1.77 \mathrm{E}-01(1.86 \mathrm{E}-02)+$ & $2.88 \mathrm{E}-02(2.16 \mathrm{E}-01)$ \\
\hline & & feasible & $2.44 \mathrm{E}+00(1.74 \mathrm{E}-02)+$ & $8.17 \mathrm{E}-01(4.32 \mathrm{E}-02)+$ & $2.55 \mathrm{E}-01(1.59 \mathrm{E}-02)+$ & $2.86 \mathrm{E}-01(8.61 \mathrm{E}-03)+$ & $2.46 \mathrm{E}-02(8.92 \mathrm{E}-02)$ \\
\hline \multirow{6}{*}{ DTLZ5 } & \multirow[b]{2}{*}{5} & infeasible & $2.16 \mathrm{E}+00(8.19 \mathrm{E}-02)+$ & $7.98 \mathrm{E}-03(1.94 \mathrm{E}-03)+$ & $4.52 \mathrm{E}-02(3.98 \mathrm{E}-03)+$ & $3.09 \mathrm{E}-01(2.83 \mathrm{E}-02)+$ & $9.57 \mathrm{E}-04(9.09 \mathrm{E}-04)$ \\
\hline & & feasible & $2.09 \mathrm{E}+00(1.62 \mathrm{E}-01)+$ & $3.95 \mathrm{E}-03(7.86 \mathrm{E}-03)=$ & $4.04 \mathrm{E}-01(1.40 \mathrm{E}-03)+$ & $2.36 \mathrm{E}-01(1.37 \mathrm{E}-02)+$ & $4.41 \mathrm{E}-03(5.06 \mathrm{E}-03)$ \\
\hline & \multirow[b]{2}{*}{8} & infeasible & $2.60 \mathrm{E}+00(3.53 \mathrm{E}-02)+$ & $2.44 \mathrm{E}-01(3.18 \mathrm{E}-02)+$ & $6.49 \mathrm{E}-01(4.54 \mathrm{E}-03)+$ & $3.95 \mathrm{E}-01(2.20 \mathrm{E}-02)+$ & $4.82 \mathrm{E}-02(3.93 \mathrm{E}-02)$ \\
\hline & & feasible & $2.63 \mathrm{E}+00(3.12 \mathrm{E}-02)+$ & $2.93 \mathrm{E}-01(2.51 \mathrm{E}-02)+$ & $1.06 \mathrm{E}+00(2.04 \mathrm{E}-03)+$ & $1.28 \mathrm{E}-01(4.26 \mathrm{E}-03)+$ & $8.58 \mathrm{E}-02(1.30 \mathrm{E}-02)$ \\
\hline & \multirow{2}{*}{10} & infeasible & $2.70 \mathrm{E}+00(3.00 \mathrm{E}-02)+$ & $6.59 \mathrm{E}-01(1.28 \mathrm{E}-01)+$ & $1.02 \mathrm{E}+00(7.99 \mathrm{E}-03)+$ & $4.78 \mathrm{E}-01(1.68 \mathrm{E}-02)+$ & $8.78 \mathrm{E}-02(9.04 \mathrm{E}-02)$ \\
\hline & & feasible & $2.72 \mathrm{E}+00(2.10 \mathrm{E}-02)+$ & $4.90 \mathrm{E}-01(2.39 \mathrm{E}-02)+$ & $1.42 \mathrm{E}+00(3.73 \mathrm{E}-03)+$ & $6.54 \mathrm{E}-01(3.53 \mathrm{E}-02)+$ & $1.58 \mathrm{E}-01(6.55 \mathrm{E}-01)$ \\
\hline \multirow{6}{*}{ DTLZ6 } & \multirow[b]{2}{*}{5} & infeasible & $9.38 \mathrm{E}+00(1.60 \mathrm{E}-01)+$ & $1.34 \mathrm{E}+00(1.21 \mathrm{E}-01)-$ & $1.19 \mathrm{E}-01(8.58 \mathrm{E}-03)-$ & $5.68 \mathrm{E}-01(6.50 \mathrm{E}-02)-$ & $1.44 \mathrm{E}+00(3.06 \mathrm{E}+00)$ \\
\hline & & feasible & $9.37 \mathrm{E}+00(1.83 \mathrm{E}-01)+$ & $2.74 \mathrm{E}-01(3.27 \mathrm{E}-02)-$ & $4.01 \mathrm{E}-01(2.22 \mathrm{E}-03)-$ & $9.69 \mathrm{E}-01(5.25 \mathrm{E}-02)-$ & $4.41 \mathrm{E}+00(1.56 \mathrm{E}+00)$ \\
\hline & \multirow{2}{*}{8} & infeasible & $1.00 \mathrm{E}+01(9.02 \mathrm{E}-02)+$ & $7.33 \mathrm{E}+00(1.10 \mathrm{E}+00)=$ & $6.63 \mathrm{E}-01(1.08 \mathrm{E}-02)-$ & $6.87 \mathrm{E}-01(5.90 \mathrm{E}-02)-$ & $5.78 \mathrm{E}+00(2.30 \mathrm{E}+00)$ \\
\hline & & feasible & $1.00 \mathrm{E}+01(3.40 \mathrm{E}-02)+$ & $4.64 \mathrm{E}-01(6.73 \mathrm{E}-02)-$ & $1.06 \mathrm{E}+00(1.78 \mathrm{E}-03)-$ & $7.58 \mathrm{E}-01(7.88 \mathrm{E}-02)-$ & $9.86 \mathrm{E}+00(3.39 \mathrm{E}-01)$ \\
\hline & \multirow{2}{*}{10} & infeasible & $1.02 \mathrm{E}+01(5.37 \mathrm{E}-02)+$ & $9.81 \mathrm{E}+00(3.17 \mathrm{E}-01)+$ & $1.02 \mathrm{E}+00(7.99 \mathrm{E}-03)-$ & $8.69 \mathrm{E}-01(3.80 \mathrm{E}-02)-$ & $6.20 \mathrm{E}+00(2.20 \mathrm{E}-01)$ \\
\hline & & feasible & $1.02 \mathrm{E}+01(4.48 \mathrm{E}-02)+$ & $7.25 \mathrm{E}-01(1.13 \mathrm{E}-01)-$ & $1.42 \mathrm{E}+00(3.53 \mathrm{E}-03)-$ & 7.44E-01(1.10E-01)- & $1.02 \mathrm{E}+01(9.97 \mathrm{E}-02)$ \\
\hline & & & $36 / 0 / 0$ & $30 / 2 / 4$ & $25 / 4 / 7$ & $25 / 1 / 10$ & \\
\hline
\end{tabular}

,$+=$ and - indicate Ra-NSGA-II performs significantly better than, equiv-

alently to, and worse than the corresponding algorithm, respectively. 
Table 6: Mean and standard deviation SP values on many-objective DTLZ

\begin{tabular}{|c|c|c|c|c|c|c|c|}
\hline Instances & $\mathrm{M}$ & $g$ & g-NSGA-II & r-NSGA-II & p-NSGA-II & WASF-GA & Ra-NSGA-II \\
\hline \multirow{6}{*}{ DTLZ1 } & \multirow{2}{*}{5} & infeasible & $4.61 \mathrm{E}+01(4.67 \mathrm{E}+00)+$ & $6.28 \mathrm{E}+00(2.41 \mathrm{E}+00)+$ & $4.43 \mathrm{E}-02(4.27 \mathrm{E}-03)=$ & $4.40 \mathrm{E}-02(6.17 \mathrm{E}-03)=$ & $3.54 \mathrm{E}-02(3.67 \mathrm{E}-03)$ \\
\hline & & feasible & $4.66 \mathrm{E}+01(4.51 \mathrm{E}+00)+$ & $1.89 \mathrm{E}+00(8.91 \mathrm{E}-01)+$ & $2.02 \mathrm{E}-02(1.60 \mathrm{E}-03)=$ & $4.07 \mathrm{E}-02(2.28 \mathrm{E}-03)=$ & $3.73 \mathrm{E}-02(4.80 \mathrm{E}-03)$ \\
\hline & \multirow{2}{*}{8} & $\begin{array}{c}\text { infeasible } \\
\text {. }\end{array}$ & $8.08 \mathrm{E}+01(4.90 \mathrm{E}+00)+$ & $1.80 \mathrm{E}+01(2.12 \mathrm{E}+00)+$ & $8.27 \mathrm{E}-02(6.30 \mathrm{E}-03)=$ & $5.26 \mathrm{E}-02(4.55 \mathrm{E}-03)=$ & $5.94 \mathrm{E}-02(1.99 \mathrm{E}-03)$ \\
\hline & & feasible & $7.83 \mathrm{E}+01(8.76 \mathrm{E}+00)+$ & $3.94 \mathrm{E}+00(6.87 \mathrm{E}-01)+$ & $3.32 \mathrm{E}-02(2.02 \mathrm{E}-03)=$ & $8.16 \mathrm{E}-02(4.32 \mathrm{E}-03)=$ & $9.97 \mathrm{E}-02(5.83 \mathrm{E}-03)$ \\
\hline & \multirow{2}{*}{10} & infeasible & $9.54 \mathrm{E}+01(1.28 \mathrm{E}+01)+$ & $2.55 \mathrm{E}+01(3.73 \mathrm{E}+00)+$ & $9.78 \mathrm{E}-02(8.05 \mathrm{E}-03)=$ & $8.90 \mathrm{E}-02(2.72 \mathrm{E}-03)=$ & $5.55 \mathrm{E}-02(1.89 \mathrm{E}-03)$ \\
\hline & & feasible & $9.53 \mathrm{E}+01(7.61 \mathrm{E}+00)+$ & $4.56 \mathrm{E}+00(3.26 \mathrm{E}-01)+$ & $4.21 \mathrm{E}-02(2.47 \mathrm{E}-03)=$ & $9.59 \mathrm{E}-02(1.43 \mathrm{E}-02)=$ & $2.37 \mathrm{E}-01(2.48 \mathrm{E}-03)$ \\
\hline \multirow{6}{*}{ DTLZ2 } & \multirow{2}{*}{5} & infeasible & $4.14 \mathrm{E}-01(3.73 \mathrm{E}-02)+$ & $1.33 \mathrm{E}-01(1.56 \mathrm{E}-02)+$ & $9.65 \mathrm{E}-02(4.88 \mathrm{E}-03)+$ & $9.47 \mathrm{E}-02(1.32 \mathrm{E}-02)+$ & $4.48 \mathrm{E}-02(3.37 \mathrm{E}-02)$ \\
\hline & & feasible & $3.84 \mathrm{E}-01(2.58 \mathrm{E}-02)+$ & $1.27 \mathrm{E}-01(1.32 \mathrm{E}-02)+$ & $9.91 \mathrm{E}-02(9.60 \mathrm{E}-03)+$ & $1.62 \mathrm{E}-01(1.46 \mathrm{E}-02)+$ & $2.42 \mathrm{E}-02(1.70 \mathrm{E}-02)$ \\
\hline & \multirow{2}{*}{8} & infeasible & $7.79 \mathrm{E}-01(5.58 \mathrm{E}-02)+$ & $2.33 \mathrm{E}-01(1.83 \mathrm{E}-02)+$ & $1.75 \mathrm{E}-01(1.31 \mathrm{E}-02)+$ & $1.86 \mathrm{E}-01(1.59 \mathrm{E}-02)+$ & $3.20 \mathrm{E}-02(2.60 \mathrm{E}-02)$ \\
\hline & & feasible & $6.61 \mathrm{E}-01(6.07 \mathrm{E}-02)+$ & $1.93 \mathrm{E}-01(2.01 \mathrm{E}-02)+$ & $1.74 \mathrm{E}-01(1.14 \mathrm{E}-02)+$ & $2.21 \mathrm{E}-01(2.50 \mathrm{E}-02)+$ & $2.70 \mathrm{E}-03(4.67 \mathrm{E}-03)$ \\
\hline & \multirow{2}{*}{10} & infeasible & $9.36 \mathrm{E}-01(9.42 \mathrm{E}-02)+$ & $2.76 \mathrm{E}-01(3.42 \mathrm{E}-02)+$ & $2.10 \mathrm{E}-01(1.53 \mathrm{E}-02)+$ & $2.29 \mathrm{E}-01(2.35 \mathrm{E}-02)+$ & $2.60 \mathrm{E}-02(1.71 \mathrm{E}-02)$ \\
\hline & & feasible & $8.30 \mathrm{E}-01(6.57 \mathrm{E}-02)+$ & $2.86 \mathrm{E}-01(3.92 \mathrm{E}-02)+$ & $2.04 \mathrm{E}-01(1.11 \mathrm{E}-02)+$ & $2.45 \mathrm{E}-01(2.73 \mathrm{E}-02)+$ & $1.27 \mathrm{E}-02(1.86 \mathrm{E}-02)$ \\
\hline \multirow{6}{*}{ DTLZ3 } & \multirow[b]{2}{*}{5} & infeasible & $2.46 \mathrm{E}+02(1.53 \mathrm{E}+01)+$ & $2.34 \mathrm{E}+01(3.43 \mathrm{E}+00)+$ & $1.02 \mathrm{E}-01(5.56 \mathrm{E}-03)+$ & $1.08 \mathrm{E}-01(1.81 \mathrm{E}-02)+$ & $5.80 \mathrm{E}-02(8.05 \mathrm{E}-02)$ \\
\hline & & feasible & $2.27 \mathrm{E}+02(3.24 \mathrm{E}+01)+$ & $2.34 \mathrm{E}+01(9.11 \mathrm{E}+00)+$ & $9.95 \mathrm{E}-02(6.30 \mathrm{E}-03)+$ & $1.81 \mathrm{E}-01(1.09 \mathrm{E}-02)+$ & $1.85 \mathrm{E}-02(5.08 \mathrm{E}-02)$ \\
\hline & \multirow{2}{*}{8} & infeasible & $5.21 \mathrm{E}+02(3.41 \mathrm{E}+01)+$ & $8.56 \mathrm{E}+01(1.58 \mathrm{E}+01)+$ & $1.74 \mathrm{E}-01(8.97 \mathrm{E}-03)+$ & $2.36 \mathrm{E}-01(2.74 \mathrm{E}-02)+$ & $1.44 \mathrm{E}-01(1.08 \mathrm{E}-02)$ \\
\hline & & feasible & $5.35 \mathrm{E}+02(3.74 \mathrm{E}+01)+$ & $8.74 \mathrm{E}+01(1.36 \mathrm{E}+01)+$ & $1.80 \mathrm{E}-01(1.07 \mathrm{E}-02)=$ & $2.08 \mathrm{E}-01(3.77 \mathrm{E}-02)+$ & $1.74 \mathrm{E}-01(1.63 \mathrm{E}-02)$ \\
\hline & \multirow{2}{*}{10} & infeasible & $7.19 \mathrm{E}+02(4.78 \mathrm{E}+01)+$ & $1.37 \mathrm{E}+02(2.55 \mathrm{E}+01)+$ & $2.05 \mathrm{E}-01(1.69 \mathrm{E}-02)=$ & $2.73 \mathrm{E}-01(3.47 \mathrm{E}-02)=$ & $2.10 \mathrm{E}-01(9.86 \mathrm{E}-02)$ \\
\hline & & feasible & $7.02 \mathrm{E}+02(4.31 \mathrm{E}+01)+$ & $1.53 \mathrm{E}+02(1.64 \mathrm{E}+01)+$ & $2.08 \mathrm{E}-01(1.79 \mathrm{E}-02)=$ & $2.63 \mathrm{E}-01(2.08 \mathrm{E}-02)=$ & $2.60 \mathrm{E}-01(1.28 \mathrm{E}-02)$ \\
\hline \multirow{6}{*}{ DTLZ4 } & \multirow[b]{2}{*}{5} & infeasible & $4.17 \mathrm{E}-01(4.15 \mathrm{E}-02)+$ & $1.49 \mathrm{E}-01(7.74 \mathrm{E}-03)+$ & $9.07 \mathrm{E}-02(3.28 \mathrm{E}-02)+$ & $9.15 \mathrm{E}-02(7.22 \mathrm{E}-03)+$ & $5.00 \mathrm{E}-02(3.46 \mathrm{E}-02)$ \\
\hline & & feasible & $3.66 \mathrm{E}-01(2.71 \mathrm{E}-02)+$ & $1.50 \mathrm{E}-01(9.49 \mathrm{E}-03)+$ & $5.43 \mathrm{E}-02(5.74 \mathrm{E}-02)+$ & $1.61 \mathrm{E}-01(2.36 \mathrm{E}-02)+$ & $3.07 \mathrm{E}-02(2.04 \mathrm{E}-02)$ \\
\hline & \multirow[b]{2}{*}{8} & infeasible & 7.67E-01(4.75E-02)+ & $2.78 \mathrm{E}-01(3.02 \mathrm{E}-02)+$ & $1.69 \mathrm{E}-01(1.04 \mathrm{E}-02)+$ & $1.81 \mathrm{E}-01(1.81 \mathrm{E}-02)+$ & $4.15 \mathrm{E}-02(3.16 \mathrm{E}-02)$ \\
\hline & & feasible & $6.70 \mathrm{E}-01(4.77 \mathrm{E}-02)+$ & $3.65 \mathrm{E}-01(3.70 \mathrm{E}-02)+$ & $1.61 \mathrm{E}-01(8.71 \mathrm{E}-03)+$ & $2.15 \mathrm{E}-01(2.57 \mathrm{E}-02)+$ & $3.75 \mathrm{E}-03(3.02 \mathrm{E}-03)$ \\
\hline & \multirow{2}{*}{10} & infeasible & $9.48 \mathrm{E}-01(8.09 \mathrm{E}-02)+$ & $3.47 \mathrm{E}-01(2.21 \mathrm{E}-02)+$ & $1.43 \mathrm{E}-01(9.91 \mathrm{E}-02)+$ & $2.16 \mathrm{E}-01(2.69 \mathrm{E}-02)+$ & $1.12 \mathrm{E}-02(2.19 \mathrm{E}-02)$ \\
\hline & & feasible & $8.11 \mathrm{E}-01(6.00 \mathrm{E}-02)+$ & 5.53E-01(4.89E-02)+ & $1.87 \mathrm{E}-01(6.60 \mathrm{E}-02)+$ & $3.54 \mathrm{E}-01(2.26 \mathrm{E}-02)+$ & $2.24 \mathrm{E}-02(6.97 \mathrm{E}-02)$ \\
\hline \multirow{6}{*}{ DTLZ5 } & \multirow[b]{2}{*}{5} & infeasible & $3.86 \mathrm{E}-01(3.32 \mathrm{E}-02)+$ & $7.63 \mathrm{E}-02(1.31 \mathrm{E}-02)+$ & $1.07 \mathrm{E}-02(3.07 \mathrm{E}-03)-$ & $2.49 \mathrm{E}-01(4.99 \mathrm{E}-02)+$ & $2.83 \mathrm{E}-02(1.79 \mathrm{E}-02)$ \\
\hline & & feasible & $3.59 \mathrm{E}-0(3.26 \mathrm{E}-02)+$ & $4.86 \mathrm{E}-02(3.23 \mathrm{E}-02)-$ & $1.05 \mathrm{E}-02(7.10 \mathrm{E}-04)-$ & $1.92 \mathrm{E}-01(2.28 \mathrm{E}-02)+$ & $8.68 \mathrm{E}-02(1.05 \mathrm{E}-02)$ \\
\hline & \multirow[b]{2}{*}{8} & infeasible & $6.72 \mathrm{E}-01(6.27 \mathrm{E}-02)+$ & $7.51 \mathrm{E}-02(8.53 \mathrm{E}-03)+$ & $4.29 \mathrm{E}-02(3.40 \mathrm{E}-03)-$ & $3.67 \mathrm{E}-01(1.27 \mathrm{E}-02)+$ & $4.60 \mathrm{E}-02(3.48 \mathrm{E}-02)$ \\
\hline & & feasible & $6.61 \mathrm{E}-01(6.22 \mathrm{E}-02)+$ & $4.22 \mathrm{E}-02(2.55 \mathrm{E}-02)+$ & $2.51 \mathrm{E}-02(1.36 \mathrm{E}-03)-$ & $1.65 \mathrm{E}-01(1.68 \mathrm{E}-02)+$ & $2.47 \mathrm{E}-02(2.82 \mathrm{E}-02)$ \\
\hline & \multirow{2}{*}{10} & infeasible & $8.33 \mathrm{E}-01(5.65 \mathrm{E}-02)+$ & $2.39 \mathrm{E}-01(3.71 \mathrm{E}-02)=$ & $6.21 \mathrm{E}-02(5.34 \mathrm{E}-03)-$ & $4.22 \mathrm{E}-01(1.33 \mathrm{E}-02)+$ & $1.51 \mathrm{E}-01(5.72 \mathrm{E}-02)$ \\
\hline & & feasible & $7.51 \mathrm{E}-01(6.05 \mathrm{E}-02)+$ & $4.37 \mathrm{E}-02(7.64 \mathrm{E}-03)=$ & $3.24 \mathrm{E}-02(2.84 \mathrm{E}-03)-$ & $2.58 \mathrm{E}-01(3.30 \mathrm{E}-02)+$ & $5.40 \mathrm{E}-02(2.75 \mathrm{E}-02)$ \\
\hline \multirow{6}{*}{ DTLZ6 } & \multirow{2}{*}{5} & infeasible & $1.52 \mathrm{E}+00(1.33 \mathrm{E}-01)+$ & $2.84 \mathrm{E}-01(3.66 \mathrm{E}-02)=$ & $2.14 \mathrm{E}-02(2.53 \mathrm{E}-03)-$ & 7.49E-01(1.39E-01)+ & $1.45 \mathrm{E}-01(2.92 \mathrm{E}-02)$ \\
\hline & & feasible & $1.46 \mathrm{E}+00(9.35 \mathrm{E}-02)+$ & $8.31 \mathrm{E}-02(7.09 \mathrm{E}-03)=$ & $1.00 \mathrm{E}-02(7.53 \mathrm{E}-04)-$ & $4.28 \mathrm{E}-01(5.60 \mathrm{E}-02)+$ & $8.35 \mathrm{E}-02(2.88 \mathrm{E}-03)$ \\
\hline & \multirow{2}{*}{8} & infeasible & $2.78 \mathrm{E}+00(1.20 \mathrm{E}-01)+$ & $2.04 \mathrm{E}+00(3.37 \mathrm{E}-01)+$ & $4.24 \mathrm{E}-02(3.69 \mathrm{E}-03)-$ & $6.41 \mathrm{E}-01(7.03 \mathrm{E}-02)+$ & $3.93 \mathrm{E}-01(2.20 \mathrm{E}-02)$ \\
\hline & & feasible & $2.71 \mathrm{E}+00(2.08 \mathrm{E}-01)+$ & $1.13 \mathrm{E}-01(2.08 \mathrm{E}-02)=$ & $2.69 \mathrm{E}-02(1.77 \mathrm{E}-03)-$ & $4.94 \mathrm{E}-01(1.68 \mathrm{E}-01)+$ & $3.10 \mathrm{E}-01(1.67 \mathrm{E}-02)$ \\
\hline & \multirow{2}{*}{10} & infeasible & $3.52 \mathrm{E}+00(1.92 \mathrm{E}-01)+$ & $3.59 \mathrm{E}+00(2.74 \mathrm{E}-01)+$ & $6.26 \mathrm{E}-02(5.50 \mathrm{E}-03)-$ & $6.05 \mathrm{E}-01(3.04 \mathrm{E}-02)+$ & $5.57 \mathrm{E}-01(1.68 \mathrm{E}-02)$ \\
\hline & & feasible & $3.42 \mathrm{E}+00(2.56 \mathrm{E}-01)+$ & $1.62 \mathrm{E}-01(4.56 \mathrm{E}-02)=$ & $3.23 \mathrm{E}-02(3.34 \mathrm{E}-03)-$ & $3.29 \mathrm{E}-01(1.08 \mathrm{E}-01)+$ & $3.96 \mathrm{E}-01(2.18 \mathrm{E}-02)$ \\
\hline $7-1$ & & & $36 / 0 / 0$ & $29 / 6 / 1$ & $15 / 9 / 12$ & $28 / 8 / 0$ & \\
\hline
\end{tabular}

,$+=$ and - indicate Ra-NSGA-II performs significantly better than, equiv-

alently to, and worse than the corresponding algorithm, respectively. 


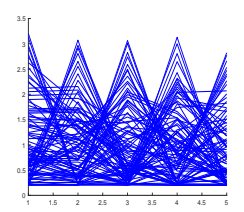

(a) g-NSGA-II

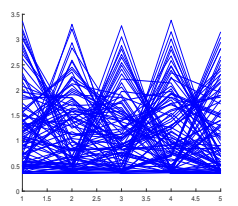

(f) g-NSGA-II

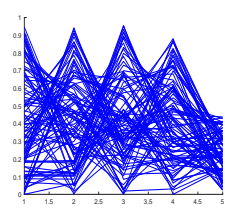

(b) r-NSGA-II

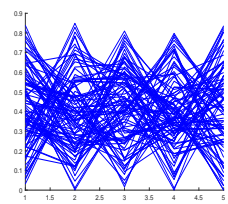

(g) r-NSGA-II

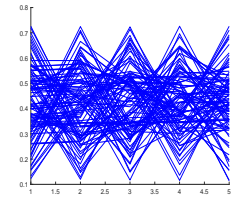

(c) p-NSGA-II

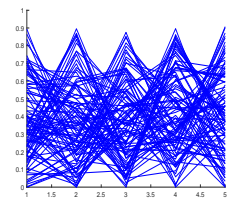

(h) p-NSGA-II

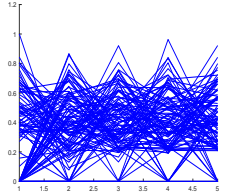

(d) WASF-GA

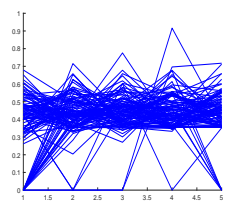

(i) WASF-GA

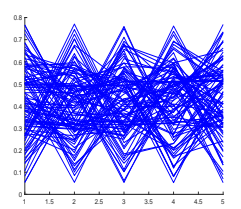

(e) Ra-NSGA-II

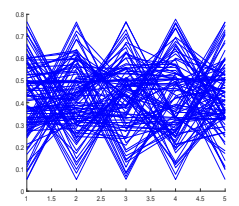

(j) Ra-NSGA-II

Figure 14: Optimal solutions on 5-obj DTLZ2 with reference point in the infeasible region: (a)-(e) and in the feasible region: (f)-(j).

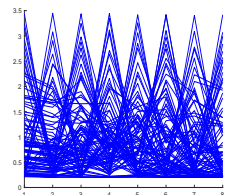

(a) g-NSGA-II

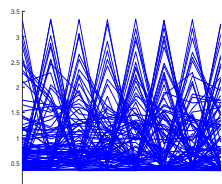

(f) g-NSGA-II

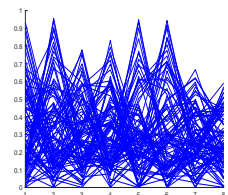

(b) r-NSGA-II

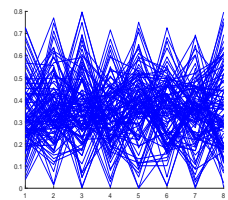

(g) r-NSGA-II

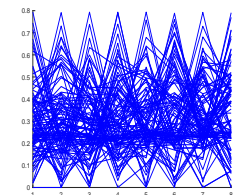

(c) p-NSGA-II

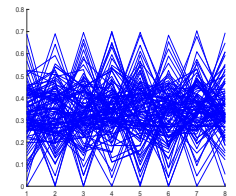

(h) p-NSGA-II
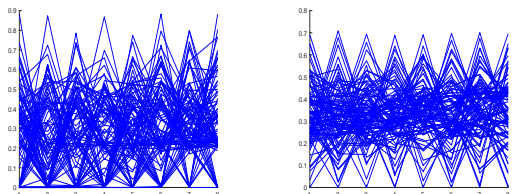

(d) WASF-GA

(e) Ra-NSGA-II

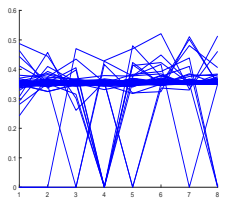

(i) WASF-GA

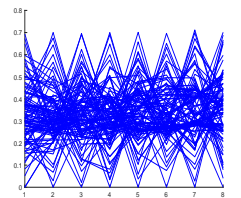

(j) Ra-NSGA-II

Figure 15: Optimal solutions on 8-obj DTLZ2 with reference point in the infeasible region: (a)-(e) and in the feasible region: (f)-(j). 


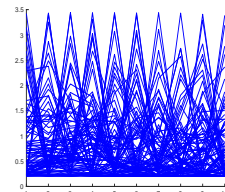

(a) g-NSGA-II

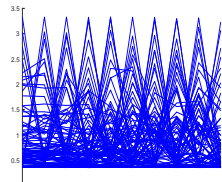

(f) g-NSGA-II

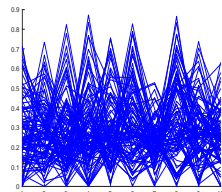

(b) r-NSGA-II

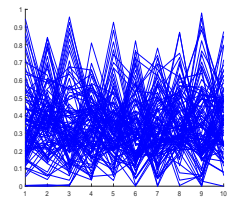

(g) r-NSGA-II

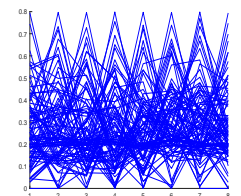

(c) p-NSGA-II

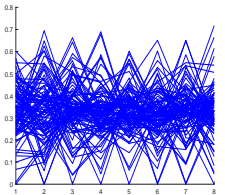

(h) p-NSGA-II

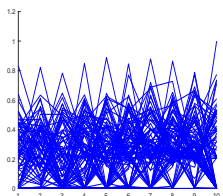

(d) WASF-GA

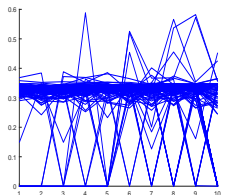

(i) WASF-GA

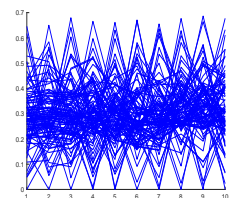

(e) Ra-NSGA-II

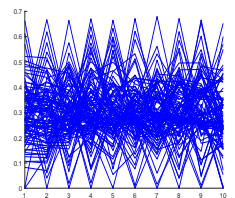

(j) Ra-NSGA-II

Figure 16: Optimal solutions on 10-obj DTLZ2 with reference point in the infeasible region: (a)-(e) and in the feasible region: (f)-(j).

the five algorithms over 30 independent runs, where the best mean and standard deviation values are colored in dark gray and the second best are highlighted in light gray. The Wilcoxon's rank sum test at a $5 \%$ significance level is conducted in this subsection, with the standard Bonferroni correction to deal with the problem of the higher probability of Type I errors in multiple comparisons.

In Table 5 it is obvious that the GD values obtained by Ra-NSGA-II are the smallest on most instances except for DTLZ1 and DTLZ6 instances. Nevertheless, the average GD of g-NSGA-II and r-NSGA-II on DTLZ1 and DTLZ3 are over 1.0, which means not converged to the PF. r-NSGA-II did not perform well on many-objective DTLZ1-4 but showed an advantage on DTLZ5-6, two dimension reduction instances. p-NSGA-II also showed great convergence on DTLZ6, and it's the second best algorithm on 8- and 10-objective DTLZ1. WASF-GA is the second best algorithm on the whole of DTLZ, it had the second best GD on most instances and even the best on DTLZ1. Ra-NSGA-II is the best on DTLZ2-5 in terms of convergence, although the performance on DTLZ1 and DTLZ6 was not good.

${ }_{435}$ In Table 6, we can see that Ra-NSGA-II has the best distribution on DTLZ2 
to DTLZ4 instances. Ra-NSGA-II also showed good distribution on DTLZ1, DTLZ5 and DTLZ6 instances when reference point in the infeasible region. pNSGA-II is also the great algorithm in distribution, it had the second best SP on most DTLZ2-4 and even the best on DTLZ5-6. It can be seen from the data comparison between Table 5 and Table 6 that WASF-GA had good convergence but poor distribution on many-objective DTLZ. On the contrast, p-NSGA-II had good distribution but not good convergence. Overall, p-NSGA-II is the best one regardless of convergence or distribution.

We randomly extracted one experimental result from 30 independent experiments. Fig 14 , Fig 15 and Fig 16 shows the obtained solutions on manyobjective DTLZ2. The true PF shape of DTLZ2 is a hypersphere and each objective of the reference point in experiment was set equal ( 0.2 or 0.35$)$, so the obtained ROI region should be symmetrical theoretically. From these figures, r-NSGA-II did not spread well on many-objective DTLZ2 as the peaks of unevenness. g-NSGA-II even can not converge to the true PF. WASF-GA was the worst distributed algorithm. Ra-NSGA-II and p-NSGA-II were the two best and closest algorithms.

\section{Conclusion}

In this paper, a new preference-based dominance relationship, Ra-dominace, has been proposed. It has the ability to help the DM to find a set of preferred solutions in the ROI. The Ra-NSGA-II can obtain the ROI with the reference point in the feasible region, infeasible region or on/close to the PF. The preference angle introduced can revise the range of the ROI according to the need of the DM. The Ra-NSGA-II had better performance compared with g-NSGA-II, r-NSGA-II, p-NSGA-II and WASF-GA on two- to ten-objective optimization problems.

One line of further research is how to apply Ra-NSGA-II to deal with the problems with complicated Pareto set shapes. Also we plan to extend it to deal with MOPs based on more than one reference point and preference angle. 
Acknowledgment

The authors would like to thank the support of the National Natural Science Foundation of China (Grant Nos. 61876164, 61673331, 61379062 and 61772178), the Education Department Major Project of Hunan Province (Grant No. 17A212), the Science and Technology Plan Project of Hunan Province (Grant No. 2018TP1036, 2016TP1020), the Provinces and Cities Joint Foundation Project (Grant No. 2017JJ4001).

\section{References}

[1] B. Li, J. Li, K. Tang, X. Yao, Many-objective evolutionary algorithms: A survey, ACM Computing Surveys (CSUR) 48 (1) (2015) 13.

[2] A. Mukhopadhyay, U. Maulik, S. Bandyopadhyay, C. A. C. Coello, A survey of multiobjective evolutionary algorithms for data mining: Part i., IEEE Trans. Evolutionary Computation 18 (1) (2014) 4-19.

[3] R. C. Purshouse, K. Deb, M. M. Mansor, S. Mostaghim, R. Wang, A review of hybrid evolutionary multiple criteria decision making methods, in: Evolutionary Computation (CEC), 2014 IEEE Congress on, IEEE, 2014, pp. $1147-1154$.

[4] K. Li, K. Deb, Q. Zhang, S. Kwong, An evolutionary many-objective optimization algorithm based on dominance and decomposition., IEEE Trans. Evolutionary Computation 19 (5) (2015) 694-716.

[5] K. Deb, S. Karthik, et al., Dynamic multi-objective optimization and decision-making using modified nsga-ii: a case study on hydro-thermal power scheduling, in: International conference on evolutionary multi-criterion optimization, Springer, 2007, pp. 803-817.

[6] A. K. Hutzschenreuter, P. A. Bosman, H. La PoutrÚ, Evolutionary multiobjective optimization for dynamic hospital resource management, in: 
International Conference on Evolutionary Multi-Criterion Optimization, Springer, 2009, pp. 320-334.

[7] J.-H. Kim, J.-H. Han, Y.-H. Kim, S.-H. Choi, E.-S. Kim, Preference-based solution selection algorithm for evolutionary multiobjective optimization, IEEE Transactions on Evolutionary Computation 16 (1) (2012) 20-34.

[8] K. Deb, A. Pratap, S. Agarwal, T. Meyarivan, A fast and elitist multiobjective genetic algorithm: Nsga-ii, IEEE transactions on evolutionary computation 6 (2) (2002) 182-197.

[9] E. Zitzler, M. Laumanns, L. Thiele, Spea2: Improving the strength pareto evolutionary algorithm, TIK-report 103.

[10] Q. Zhang, H. Li, Moea/d: A multiobjective evolutionary algorithm based on decomposition, IEEE Transactions on evolutionary computation 11 (6) (2007) 712-731.

[11] H. Li, Q. Zhang, Multiobjective optimization problems with complicated pareto sets, moea/d and nsga-ii, IEEE Transactions on evolutionary computation 13 (2) (2009) 284-302.

[12] K. Deb, H. Jain, An evolutionary many-objective optimization algorithm using reference-point-based nondominated sorting approach, part i: Solving problems with box constraints., IEEE Trans. Evolutionary Computation 18 (4) (2014) 577-601.

[13] L. Fu, J. Zou, S. Yang, G. Ruan, Z. Ma, J. Zheng, A proportion-based selection scheme for multi-objective optimization, in: Computational Intelligence (SSCI), 2017 IEEE Symposium Series on, IEEE, 2017, pp. 1-7.

[14] Q. Li, J. Zou, S. Yang, J. Zheng, G. Ruan, A predictive strategy based on special points for evolutionary dynamic multi-objective optimization, Soft Computing (2018) 1-17. 
[15] G. Ruan, G. Yu, J. Zheng, J. Zou, S. Yang, The effect of diversity maintenance on prediction in dynamic multi-objective optimization, Applied Soft Computing 58 (2017) 631-647.

[16] J. Zou, Y. Zhang, S. Yang, Y. Liu, J. Zheng, Adaptive neighborhood selection for many-objective optimization problems, Applied Soft Computing.

[17] S. Jiang, S. Yang, A strength pareto evolutionary algorithm based on reference direction for multiobjective and many-objective optimization, IEEE Transactions on Evolutionary Computation 21 (3) (2017) 329-346.

[18] S. F. Adra, I. Griffin, P. J. Fleming, A comparative study of progressive preference articulation techniques for multiobjective optimisation, in: International Conference on Evolutionary Multi-Criterion Optimization, Springer, 2007, pp. 908-921.

[19] R. Wang, R. C. Purshouse, I. Giagkiozis, P. J. Fleming, The ipicea-g: a new hybrid evolutionary multi-criteria decision making approach using the brushing technique, European Journal of Operational Research 243 (2) (2015) 442-453.

[20] Y. Jin, B. Sendhoff, Incorporation of fuzzy preferences into evolutionary multiobjective optimization, in: Genetic and Evolutionary Computation Conference, 2002, p. 683.

[21] B. Xin, C. Lu, C. Jie, H. Ishibuchi, K. Hirota, L. Bo, Interactive multiobjective optimization: A review of the state-of-the-art, IEEE Access 6 (2018) 41256-41279.

[22] B. Luo, L. Lin, S. Zhong, Pga/moead: a preference-guided evolutionary algorithm for multi-objective decision-making problems with interval-valued fuzzy preferences, International Journal of Systems Science 49 (3) (2018) 595-616. 
[23] A. Sarjaš, A. Chowdhury, R. Svečko, Multi-criteria optimal pole assignment robust controller design for uncertainty systems using an evolutionary algorithm, International Journal of Systems Science 47 (12) (2016) 2792-2807.

[24] J. Hu, G. Yu, J. Zheng, J. Zou, A preference-based multi-objective evolutionary algorithm using preference selection radius, Soft Computing 21 (17) (2017) 5025-5051.

[25] C. M. Fonseca, P. J. Fleming, et al., Genetic algorithms for multiobjective optimization: Formulationdiscussion and generalization., in: Icga, Vol. 93, 1993, pp. 416-423.

[26] C. M. Fonseca, P. J. Fleming, Multiobjective genetic algorithms made easy: selection sharing and mating restriction.

[27] D. Cvetkovic, I. C. Parmee, Genetic algorithm-based multi-objective optimisation and conceptual engineering design, in: Evolutionary Computation, 1999. CEC 99. Proceedings of the 1999 Congress on, Vol. 1, IEEE, 1999, pp. 29-36.

[28] D. Cvetkovic, I. C. Parmee, Preferences and their application in evolutionary multiobjective optimization, IEEE Transactions on evolutionary computation 6 (1) (2002) 42-57.

[29] J. Molina, L. V. Santana, A. G. Hernández-Díaz, C. A. C. Coello, R. Caballero, g-dominance: Reference point based dominance for multiobjective metaheuristics, European Journal of Operational Research 197 (2) (2009) 685-692.

[30] L. B. Said, S. Bechikh, K. Ghédira, The r-dominance: a new dominance relation for interactive evolutionary multicriteria decision making, IEEE Transactions on Evolutionary Computation 14 (5) (2010) 801-818.

[31] K. Deb, J. Sundar, Reference point based multi-objective optimization using evolutionary algorithms, in: Proceedings of the 8th annual conference on Genetic and evolutionary computation, ACM, 2006, pp. 635-642. 
[32] K. Deb, A. Sinha, P. J. Korhonen, J. Wallenius, An interactive evolutionary multiobjective optimization method based on progressively approximated value functions, IEEE Transactions on Evolutionary Computation 14 (5) (2010) 723-739.

[33] J. Branke, J. Branke, K. Deb, K. Miettinen, R. Slowiński, Multiobjective optimization: Interactive and evolutionary approaches, Vol. 5252, Springer Science \& Business Media, 2008.

[34] K. Deb, A. Kumar, Interactive evolutionary multi-objective optimization and decision-making using reference direction method, in: Proceedings of the 9th annual conference on Genetic and evolutionary computation, ACM, 2007, pp. $781-788$.

[35] K. Deb, A. Kumar, Light beam search based multi-objective optimization using evolutionary algorithms., in: IEEE Congress on Evolutionary Computation, 2007, pp. 2125-2132.

[36] S. Greco, V. Mousseau, R. Słowiński, Ordinal regression revisited: multiple criteria ranking using a set of additive value functions, European Journal of Operational Research 191 (2) (2008) 416-436.

[37] A. B. Ruiz, R. Saborido, M. Luque, A preference-based evolutionary algorithm for multiobjective optimization: the weighting achievement scalarizing function genetic algorithm, Journal of Global Optimization 62 (1) (2015) 101-129.

[38] G. Yu, J. Zheng, R. Shen, M. Li, Decomposing the user-preference in multiobjective optimization, Soft Computing 20 (10) (2016) 4005-4021.

[39] D. A. Van Veldhuizen, G. B. Lamont, Evolutionary computation and convergence to a pareto front, in: Late breaking papers at the genetic programming 1998 conference, 1998, pp. 221-228. 
[40] J. R. Schott, Fault tolerant design using single and multicriteria genetic algorithm optimization., Tech. rep., AIR FORCE INST OF TECH WRIGHT-PATTERSON AFB OH (1995).

[41] F. Wilcoxon, Individual comparisons by ranking methods, in: Breakthroughs in statistics, Springer, 1992, pp. 196-202.

[42] H. Abdi, Bonferroni and šidák corrections for multiple comparisons, Encyclopedia of measurement and statistics 3 (2007) 103-107. 